\title{
TENDÊNCIAS E DIFERENCIAIS SOCIOECONÔMICOS DA MORTALIDADE POR CÂNCER BUCAL E DE GLÂNDULAS SALIVARES NO MUNICÍPIO DE SÃO PAULO, DE 1980 A 2000
}

MARIA GABRIELA HAYE BIAZEVIC

Tese de Doutorado apresentada à Faculdade de Saúde Pública da Universidade de São Paulo para obtenção do Grau de Doutor.

Área de concentração: Serviços de Saúde Pública

ORIENTADOR: PROF. DR. ROBERTO AUGUSTO CASTELLANOS FERNANDEZ

São Paulo 
A Michel, com todo o meu amor, Aos meus pais, Daniza e Juan, Aos meus irmãos, Daniza e Paulo, Aos meus sogros, Cristina e Edgard, A Teresa e Wagner 


\section{AGRADECIMENTOS}

Ao Prof. Dr. Roberto Augusto Castellanos Fernandez, por me dar a oportunidade de continuar a tão sonhada jornada acadêmica.

Ao Prof. Dr. José Leopoldo Ferreira Antunes, da Faculdade de Odontologia da USP, pelo inestimável auxillio na elaboração deste trabalho, bem como por permitir-me um aprendizado constante.

À Prof ${ }^{a}$. Dr ${ }^{a}$. Maria Ercilia de Araujo, Chefe do Departamento de Odontologia Social da Faculdade de Odontologia da USP, pela amizade e apoio.

Ao Prof. Carlos Alfredo Salles Loureiro, pela amizade e pela maneira como sempre soube me motivar a procurar a melhor evidência para os problemas cientificos.

Aos amigos da UniFMU e da FOUSP, Simone Rennó Junqueira e Antonio Carlos Frias, pela amizade, compreensão e apoio.

Às colegas da UNISANTA, Kátia Regina Esquivel Andrade e Edna Alves Silva, pela magnífica convivência e constante aprendizado proporcionado em nossas aulas.

Aos colegas da UNICSUL, Márcia Roberti da Silva e Pierangelo Angeletti, pela convivência e harmonia com que realizávamos nossas atividades naquela Instituição. 
À Prof ${ }^{\text {. Dra }}$. Nemre Adas Saliba, da Faculdade de Odontologia da Universidade Estadual Paulista (UNESP), pela calorosa acolhida quando de minha passagem por Araçatuba.

À Universidade do Oeste de Santa Catarina (UNOESC), Campus JoaçabaSC: à Pró-Reitoria de Administração, na pessoa do Prof. Aristides Cimadon, à Vice-Reitoria de Pesquisa, Extensão e Pós-Graduação, na pessoa do Prof. Luiz Carlos Lückmann, e à Pró-Reitoria de Ensino, na pessoa da Prof ${ }^{a}$. Dorvalina Lange, por viabilizarem, tanto financeira quanto intelectualmente, a conclusão deste trabalho.

Agradecimento especial à direção do Centro de Ciências Biológicas e da Saúde (CCBS) da UNOESC, na pessoa do Prof. Adgar Zefferino Bittencourt, pelo apoio necessário tanto para a realização deste trabalho, como para o desenvolvimento das diversas atividades acadêmicas na UNOESC Joaçaba. 


\section{RESUMO}

Biazevic MGH. Tendências e diferenciais socioeconômicos da mortalidade por câncer bucal e de glândulas salivares no Município de São Paulo, de 1980 a 2000. São Paulo; 2003. [Tese de Doutorado Faculdade de Saúde Pública da USP].

Objetivo. Discutir a evolução da mortalidade por câncer bucal e de glândulas salivares no município de São Paulo, entre 1980 e 2000, bem como associar tal condição a indicadores de desigualdade social. Métodos. Os dados sobre mortalidade por câncer bucal no período foram levantados a partir do banco de dados da Fundação Sistema Estadual de Análise de Dados (SEADE), segundo os códigos 140.0 a 145.9 da ga edição da Classificação Internacional de Doenças (CID-9) e C00.0 a C08.9 de sua 10a. edição, com discriminação por sexo, localização anatômica e distrito de residência. Os dados populacionais do municipio foram obtidos por meio dos censos de 1980, 1991, contagem populacional de 1996 e censo 2000, no Instituto Brasileiro de Geografia e Estatística (IBGE). Os indicadores de condição social dos distritos da cidade foram levantados a partir da Secretaria Municipal de Planejamento Urbano e dos recenseamentos gerais de população. Realizou-se uma análise de tendência da evolução recente da mortalidade por local, e um estudo ecológico para a associação de indicadores de mortalidade por câncer bucal e de glândulas salivares e condição sócio-econômica por área do município. A presente pesquisa envolveu apenas o estudo documental de dados secundários e de literatura. Resultados. Câncer de língua foi responsável por quase $50 \%$ dos óbitos no período de 1980 e 2000. A maioria das localizações anatômicas apresentou tendência estável, com exceção de câncer de lábio e de gengiva, que apresentaram declínio, e partes não especificadas da cavidade bucal, que apresentou tendência de aumento. Para todos as localizações anatômicas, homens foram mais acometidos que mulheres, numa proporção de 3:1. Houve correlação de $-0,238(p=0,009)$ para anos de estudo e risco de óbito 
por câncer bucal; com relação ao chefe da família sem instrução ou com $1^{\circ}$ grau incompleto, houve correlação positiva de $0,200(p=0,025)$, e de $-0,341$ $(p<0,001)$ para chefe da família com formação universitária, além de $-0,362$ $(p<0,001)$ para renda média familiar, $-0,268(p=0,004)$ para presença de domicilio quitado, e coeficiente de Gini com correlação de $0,275 \quad(p=0,004)$ relacionado ao risco de óbito por câncer bucal e de glândulas salivares. Distritos com maior proporção de óbitos possuíam piores indicadores de desenvolvimento social, sugerindo que o risco de óbito por câncer bucal e de glândulas salivares se relaciona de maneira estreita com iniqüidades sociais relacionadas à saúde.

Descritores: Câncer Bucal. Epidemiologia. Tendências. Iniqüidade. Mortalidade. 


\section{SUMMARY}

Biazevic MGH. Tendências e diferenciais socioeconômicos da mortalidade por câncer bucal e de glândulas salivares no Município de São Paulo, de 1980 a 2000 [Trends and socioeconomical differentials of oral cancer and salivary glands mortality in the city of São Paulo, Brazil, 19802000]. São Paulo (BR); 2003 [Tese de Doutorado - Faculdade de Saúde Pública da Universidade de São Paulo].

Objective. To discuss the evolution of oral cancer and salivary glands mortality in the city of São Paulo, Brazil, between 1980 and 2000, and associate this condition indices of socioeconomic status. Methods. The State System of Data Analysis (SEADE) supplied information on oral cancer mortality (codes $140.0-145.9$, International Classification of Diseases, $9^{\text {th }}$ edition, ICD-9, and codes C00.8- C08.9, ICD-10), discriminated by gender, anatomic localization and area of residence. Population data were gathered from census performed in 1980,1991, 1996 and 2000. The same source and the Municipal Secretary of Urban Planning provided information to the appraisal of indices of socioeconomic status. The assessment of mortality rates included trend analysis and area-level correlation with demographic covariants. This study only gathered non-primary data and literature. Results. Tongue was the most prevalent site of oral cancer deaths, with almost $50 \%$ in the $1980-2000$ period. Most anatomic sites presented stationary trend, excepting lip and gum cancer, which declined, and nonspecified parts of the mouth, which increased. Overall rates of oral cancer and salivary glands mortality were three times higher for men than women. At the area level, oral cancer and salivary glands death rates associated with the average member of years of study (Pearson $r=-0.238, p=0.009$ ). Death rated correlated positively with the proportion of heads of the household without inclusion (Pearson $r=0.200, p=0.025$ ) and the Gini coefficient (Pearson $r=0.275, p=0.004$ ), and negatively with income (Pearson $r=$ $0.341, p<0.001$ ) and household ownership (Pearson $r=0.268, p=0.004$ ). 
Areas with higher death rates presented worse indices of socioeconomic status, indicating the risk of death by oral cancer and salivary glands is associated with social inequities affecting health.

Descriptors: Oral Cancer. Epidemiology. Trends. Iniquity. Mortality. 


\section{ÍNDICE}

LISTA DE TABELAS E QUADROS

LISTA DE FIGURAS

1 INTRODUÇÃO

2 REVISÃO DA LITERATURA

2.1 Epidemiologia do Câncer Bucal

2.2 Iniqüidade e Saúde

2.3 Agregados domiciliares e condição socioeconômica

3 OBJETIVOS

3.1 Objetivo Geral

3.2 Objetivos Específicos

4 MÉTODOS

5 RESULTADOS

6 DISCUSSÃO

7 CONCLUSÕES

8 REFERÊNCIAS

ANEXO

Ofício COEP/51/02. Aprovação do Protocolo de Pesquisa pelo Comitê de Ética em Pesquisa da Faculdade de Saúde Pública da USP 


\section{LISTA DE TABELAS E QUADROS}

página

Quadro 4.1. Equivalências dos códigos da $9^{\mathrm{a}}$ e $10^{\mathrm{a}}$ revisões da 39 Classificação Internacional das Doenças.

Tabela 5.1. Freqüências absoluta e relativa e tendência dos 44 óbitos por câncer bucal segundo a localização anatômica da lesão, Município de São Paulo, 1980-2000.

Quadro 5.1. Distritos correspondentes ao conglomerado com 56 menor risco de óbito por câncer bucal, população de cada distrito, e coeficiente de mortalidade padronizado por sexo e faixa etária por 100.000 habitantes para o Município de São Paulo, período de 1994 a 2000.

Quadro 5.2. Distritos correspondentes ao conglomerado com o segundo menor risco de óbito por câncer bucal, população de 57 cada distrito, e coeficiente de mortalidade padronizado por sexo e faixa etária por 100.000 habitantes para o Município de São Paulo, periodo de 1994 a 2000.

Quadro 5.3. Distritos correspondentes ao conglomerado com o 58 terceiro menor risco de óbito por câncer bucal, população de cada distrito, e coeficiente de mortalidade padronizado por sexo e faixa etária por 100.000 habitantes para o Município de São Paulo, período de 1994 a 2000. 
Quadro 5.4. Distritos correspondentes ao conglomerado com o segundo maior risco de óbito por câncer bucal população de cada distrito, e coeficiente de mortalidade padronizado por sexo e faixa etária por 100.000 habitantes para o Municipio de São Paulo, período de 1994 a 2000.

Quadro 5.5. Distritos correspondentes ao conglomerado com o 60 maior risco de óbito por câncer bucal, população de cada distrito, e coeficiente de mortalidade padronizado por sexo e faixa etária por 100.000 habitantes para o Município de São Paulo, periodo de 1994 a 2000.

Tabela 5.2. Informações sociodemográficas segundo 60 conglomerados de áreas classificadas pelo risco de óbito por câncer bucal no Município de São Paulo, 2000.

Tabela 5.3. Coeficientes de correlação ' $r$ ' de Pearson dos indicadores socioeconômicos com o coeficiente padronizado de mortalidade por câncer bucal, Município de São Paulo, 1980-2000.

Tabela 5.4. Razão entre os coeficientes de mortalidade dos 65 conglomerados com pior condição socioeconômica com os de melhor condição socioeconômica em relação às localizações anatômicas causadoras de óbitos por câncer bucal no Município de São Paulo, 2002. 


\section{LISTA DE FIGURAS}

Página

Figura 5.1. Coeficiente padronizado (por gênero e grupo 46 etário) ) e alisado (MM5) de mortalidade por câncer bucal (códigos C00.0 - C08.9 da CID-10) por 100.000 habitantes para o município de São Paulo, 1980-2000.

Figura 5.2. Coeficiente padronizado (por grupo etário) e alisado (MM5) masculino e feminino de mortalidade por câncer bucal por 100.000 habitantes segundo o sexo e ambos, para o município de São Paulo, 1980-2000.

Figura 5.3. Coeficiente padronizado (por gênero e grupo etário) e alisado (MM5) de mortalidade por neoplasia no assoalho de boca (códigos C04.0 - C04.9 da CID-10) por 100.000 habitantes para o município de São Paulo, 19802000.

Figura 5.4. Coeficiente padronizado (por gênero e grupo 49 etário) e alisado (MM5) de mortalidade por neoplasia na gengiva (códigos C03.0 - C03.9 da CID-10) por 100.000 habitantes para o município de São Paulo, 1980-2000.

Figura 5.5. Coeficiente padronizado (por gênero e grupo 50 etário) e alisado (MM5) de mortalidade por neoplasia em glândulas salivares (códigos $\mathrm{C} 07$ - C08.9 da CID-10) por 100.000 habitantes para o municipio de São Paulo, 19802000. 
Figura 5.6. Coeficiente padronizado (por gênero e grupo

etário) e alisado (MM5) de mortalidade por neoplasia em lábio (códigos C00.0 - C00.9 da CID-10) por 100.000 habitantes para o município de São Paulo, 1980-2000.

Figura 5.7. Coeficiente padronizado (por gênero e grupo 52 etário) e alisado (MM5) de mortalidade por neoplasia na língua (códigos C01 - C02.9 da CID-10) por 100.000 habitantes para o município de São Paulo, 1980-2000.

Figura 5.8. Coeficiente padronizado (por gênero e grupo 53 etário) e alisado (MM5) de mortalidade por neoplasia em partes não especificadas da boca (código C06.9 da CID-10) por 100.000 habitantes para o municipio de São Paulo, 19802000.

Figura 5.9. Coeficiente padronizado (por gênero e grupo etário) e alisado (MM5) de mortalidade por neoplasia no palato (códigos C05.0 - C05.9 da CID-10) por 100.000 habitantes para o município de São Paulo, 1980-2000.

Figura 5.10. Coeficiente padronizado (por gênero e grupo etário) e alisado (MM) de mortalidade por neoplasia na região retromolar (código C06.2 da CID-10) por 100.000 habitantes para o município de São Paulo, 1980-2000.

Figura 5.11. Distribuição espacial dos distritos segundo o 62 coeficiente de mortalidade por câncer bucal. Município de São Paulo, 2002.

Figura 5.12. Série temporal da tendência dos óbitos por câncer bucal segundo conglomerados. Município de São Paulo, 199463 2001. 


\section{INTRODUÇÃO}

As doenças não-infecciosas constituem uma área de atuação importante da epidemiologia aplicada. Segundo PEREIRA (1995), o grupo de doenças não-infecciosas que atingem as populações é muito variado, podendo receber outras denominações, tais como doenças "não transmissíveis", "crônico-degenerativas" e "crônico não-transmissíveis". Embora esses conceitos sejam empregados de forma errônea como sinônimos e seja difícil encontrar uma denominação adequada, esses grupos de manifestações possuem características comuns. Uma característica importante desse grupo consiste em não serem transmitidas de uma pessoa para outra e possuírem uma etiologia multicausal.

As doenças não-infecciosas, segundo ROUQUAYROL (1999) constituem uma das principais causas de mortalidade no Brasil, que ainda não se libertou da alta mortalidade das doenças transmissiveis como dengue, cólera e AIDS.

A análise epidemiológica dos indicadores de mortalidade das doenças crônicas não-transmissiveis é de fundamental importância para detectar as tendências e levantar hipóteses etiológicas.

No Brasil, as doenças não-infecciosas começaram a ter importância crescente nas estatísticas de mortalidade e as neoplasias começaram a ganhar destaque, como indicam MIRRA et al. (2001). Segundo os autores, 
no periodo de 1930-1998, a evolução da mortalidade proporcional pelas neoplasias malignas no Município de São Paulo contrastou de muito com as doenças infecciosas e parasitárias, passando de $4,2 \%$ para $16,0 \%$; as doenças infecto-parasitárias passaram de $39,0 \%$ para $3,1 \%$ (excluindo a AIDS).

Segundo estatísticas de mortalidade do Ministério da Saúde, no ano de 1994 , as neoplasias se apresentaram como a quarta causa de morte no território brasileiro; excluindo-se as causas maldefinidas, as neoplasias passam para o terceiro posto (MINISTÉRIO DA SAÚDE, 1997).

De acordo com o Instituto Nacional do Câncer (INCA, 2002),

"Analisando-se as taxas de mortalidade das macrorregiões do Brasil, o câncer é encontrado em diferentes posições, mas sempre incluido entre as primeiras causas de morte, ao lado das doenças do aparelho circulatório, causas externas, doenças do aparelho respiratório, afecções do período peri-natal e doenças infecciosas e parasitárias.

(...) exceto pela Região Sul, as causas externas foram, em 1994, o segundo maior grupo de causas de morte, no Brasil, e (...), na Região Norte, as afecções peri-natais constituíram, neste mesmo ano, a terceira causa de morte por doença, superando as doenças infecto-parasitárias e as do aparelho respiratório. 
(...) o câncer se constitui na segunda causa de morte por doença, no Brasil, e, em 1994, os neoplasmas foram responsáveis por $10,86 \%$ dos 887.594 óbitos registrados, sendo que $53,81 \%$ dos óbitos por neoplasia ocorreram entre os homens e $46,05 \%$, entre as mulheres. Somente na Região Nordeste, as neoplasias representam a terceira causa de morte por doença, consistindo de $6,34 \%$ dos óbitos atestados, ficando apenas 0,02 pontos percentuais depois das doenças infecciosas e parasitárias. Nas demais regiões, os neoplasmas seguem-se às doenças cárdiovasculares, como causa de morte, e sua proporcionalidade aumenta à medida que se desloca para o sul: $7,83 \%$ (Região Norte), $9,89 \%$ (Região Centro-Oeste), $11,93 \%$ (Região Sudeste) e 15,19\% (Região Sul). “ (INCA, 2002).

"Câncer bucal" é uma categoria abrangente de localização para neoplasias, e inclui tumores de diferentes etiologias e perfis histológicos, embora majoritariamente se refira ao carcinoma epidermóide. A característica multifatorial de sua etiologia integra fatores endógenos, como a predisposição genética, e fatores exógenos ambientais e comportamentais, de cuja integração pode resultar o desenvolvimento do agravo.

MOORE e PEARCE (2000) explicam que o termo mais geral "câncer de boca" é passível de gerar confusões. Sugerem que os pesquisadores poderiam referenciar os seguintes subgrupos: lábio (código 140 da $9^{\text {a }}$ edição 
da Classificação Internacional de Doenças - CID-9, ou C00.0 da CID-10), intra-oral ou da cavidade bucal (códigos 143-145 da CID-9 ou C01-C06 da CID-10), e glândulas salivares maiores (código 142 da CID-9 ou C07-C08 da CID-10). Independentemente do tipo de câncer de boca (considerando-o um termo genérico) utilizado, os autores alertam para a necessidade dos pesquisadores esclarecerem essa questão em seus estudos.

Os fatores mais comumente associados ao aumento do risco de câncer de boca são o tabagismo (BURT e EKLUND, 1999; GUPTA et al., 1984) e o etilismo (GUPTA, 1984). A exposição freqüente à luz solar tem sido relatada como fator de aumento do risco para câncer de lábio, em especial afetando pessoas que trabalham em ambiente externo, como estivadores, portuários e trabalhadores da construção civil (MOORE et al, 1999; HAKANSSON et al., 2001). Ademais, a preocupação quanto aos hábitos alimentares como possíveis fatores de risco ou proteção para câncer bucal tem aumentado consideravelmente. Ao rever estudos epidemiológicos que analisavam fatores culturais e alimentares, ZAIN (2001) relatou a associação de uma dieta mais pobre em nutrientes com o risco de desenvolvimento de neoplasias bucais e lesões cancerizáveis.

Os fatores ambientais também têm sido citados como colaboradores do aumento da incidência de câncer labial, bucal e de faringe, segundo MORSE et al. (1999). No Japão, encontrou-se também uma tendência de aumento do câncer bucal e de faringe (SU et al., 1999).

CHEN (1991), por sua vez, observou um descréscimo nas taxas de câncer bucal nos Estados Unidos para os homens, ao passo de que para as 
mulheres, observou um aumento; ainda assim, encontra-se maior proporção do agravo em homens (NEVES, 1994).

O conhecimento acumulado da etiologia do câncer não tem sido aplicado com a eficiência necessária para possibilitar uma redução substancial na incidência de certos tipos de câncer (TOMATIS, 1997). Tem sido observado que a sobrevivência de pacientes com câncer em países sub-desenvolvidos é de $1 / 3$ da dos países desenvolvidos (TOMATIS, 1997), o que possivelmente sugere que se possa relacionar a doença a diversas condições de iniqüidades no mundo.

"O princípio da igualdade tem base no conceito de cidadania, segundo o qual todos os indivíduos são iguais, tendo, portanto, os mesmos direitos. Mas igualdade não é o mesmo que eqüidade. Esta incorpora em seu conceito algum valor de justiça. Por outro lado, nem toda desigualdade constitui iniqüidade no sentido de injustiça. A iniqüidade pode ser considerada como uma "desigualdade injusta", que poderia ser evitada, daí sua importância para os tomadores de decisão." (VIANA et al., 2001)

Estudos epidemiológicos sublinham a desigualdade na distribuição de câncer bucal em diferentes grupos populacionais, realçando a associação da condição social com o risco da doença. MACFARLANE et al. (1996) atribuíram a evolução desfavorável da mortalidade por câncer de boca, língua e faringe na Escócia, entre 1968 e 1992, ao maior incremento de incidência nas áreas com piores indicadores sociais, nas quais a 
sobrevivência ao agravo era mais baixa. O'HANLON, FORSTER e LOWRY (1997) também associaram incidência e mortalidade por câncer bucal num contexto europeu, como associados à privação material. Estudos realizados no Brasil também têm identificado a falta de eqüidade social como fator associado ao câncer bucal (ANTUNES et al, 2001; MACIEL et al., 2000), com ênfase nas disparidades de renda, nível educacional e indices compostos de desenvolvimento humano.

O estudo da associação entre câncer bucal e privação social é complexo e sugere diferentes possibilidades. Por um lado, condições precárias de vida e trabalho podem se associar à exposição mais intensa aos fatores de risco. Por outro lado, a estratificação social da doença pode também refletir padrões diferenciais de acesso a informações e serviços de saúde: em geral, os grupos populacionais mais submetidos à privação social são menos susceptíveis à mudança de comportamento, dispõem de menos recursos terapêuticos, menor acesso a um diagnóstico precoce e pior prognóstico quando desenvolvem o agravo. Tal associação tem sido discutida também para outros problemas de saúde pública, como cárie dentária (PATTUSI et al., 2001) e violência (MACEDO, 2001).

O presente estudo se propõe a contribuir para o debate referente à associação entre os indicadores de desenvolvimento social e câncer bucal, estudando a tendência recente de evolução dos indicadores de mortalidade no Município de São Paulo, e levantando diferentes hipóteses de associação desses indicadores com os indices de condição social dos distritos da cidade. 


\section{REVISÃO DA LITERATURA}

\subsection{Epidemiologia do Câncer Bucal}

SMITH e PATH (1973), ao realizar uma revisão sobre a epidemiologia do câncer bucal no mundo e seus fatores etiológicos, afirmam que o diagnóstico de tumores de dimensões diminutas e localizados está seguido de maiores taxas de sobrevivência. Além disso, os autores comentam a notoriedade dos fatores etiológicos comumente envolvidos - luz solar, consumo de tabaco em diferentes formas, álcool, sifilis, e Síndrome de Plummer-Vinson -, que parecem exercer maior efeito em locais específicos da mucosa bucal, ao invés de todas as partes por igual. A importância dos fatores de condição odontológica, tais como higiene bucal inadequada e próteses mal-adaptadas na etiologia do câncer bucal permanece incerta, e as lesões bucais cancerizáveis, principalmente a leucoplasia, demonstram uma suscetibilidade incrementada para o desenvolvimento de câncer bucal.

Ao revisar uma série de estudos epidemiológicos realizados para detectar a epidemiologia do câncer bucal, PINDBORG (1977) explica que a sua incidência mostra claras diferenças geográficas, relacionadas principalmente a fatores ambientais. Na maioria dos estudos por ele relatados, o uso do tabaco, nas suas diversas formas, mostrou-se como um fator a ser destacado como forte causador de lesões. Relatando as 
informações publicadas pelo Registro de Câncer da Noruega em 1973, PINDBORG (1977) destaca que o câncer de lábio foi 20 vezes mais freqüente entre homens do que em mulheres, e ocorreu com o dobro da freqüência em áreas rurais, comparativamente a áreas urbanas. $O$ autor comenta também a tendência de decréscimo que tem sido observada para esta localização anatômica de câncer no mesmo pais.

Em levantamento domiciliar realizado no Estado de Kerala, Índia, 10.914 indivíduos moradores da zona rural foram entrevistados a respeito de seus hábitos de uso de tabaco e álcool, além de examinados com relação à presença de leucoplasia (GUPTA, 1984). Todos os indivíduos eram usuários regulares de tabaco sob alguma forma. Os exames bucais foram realizados por dentistas calibrados, utilizando-se de luz natural e cadeira odontológica portátil. Os consumidores de álcool foram divididos em 3 categorias: usuários regulares (que consumiam bebidas alcoólicas pelo menos 3 vezes por semana), consumidores ocasionais e não consumidores. Não foi feita estimativa quantitativa a respeito da quantidade de álcool ingerido. Como poucas mulheres $(1,6 \%)$ relataram serem consumidoras de álcool, elas foram excluídas do estudo; o autor encontrou que a prevalência de leucoplasia foi significativamente maior entre os consumidores regulares $(5,7 \%)$ e ocasionais $(3,9 \%)$ de álcool.

Uma amostra representativa de vilas no distrito de Srikakulam, Sul da India, foi selecionada e 10.169 pessoas com mais de 15 anos de idade foram entrevistadas sobre seus hábitos de uso de tabaco, em 1967 (GUPTA et al., 1984). Três anos depois, esses indivíduos foram novamente 
entrevistados, e repetidamente de forma anual nos 10 anos seguintes. A proporção de indivíduos seguidos durante o periodo foi de $87 \%$; correspondendo aos individuos que passaram pelo exame bucal (GUPTA et al., 1984). Da amostra original, $47 \%$ praticavam o "reverse smoking" (fumadores de cigarro com a ponta acesa de maneira invertida, ou seja, para o interior da cavidade bucal). Os autores observaram que o hábito de consumo de tabaco não variou durante o período estudado. Tanto para homens quanto para mulheres, as taxas ajustadas de mortalidade foram de aproximadamente duas vezes maiores entre os praticantes do "reverse smoking" do que entre os participantes que não costumavam consumir qualquer tipo de tabaco. GUPTA et al. (1984) explicam ainda que o câncer bucal foi responsável por apenas uma fração do excesso de mortalidade entre os consumidores de tabaco. Os autores explicam ainda que a condição socioeconômica da população estudada era bastante semelhante e em geral, as vilas onde o estudo foi realizado não contavam com profissionais de saúde com qualificação específica.

Em artigo de revisão que levantou as condições de saúde bucal relacionadas ao câncer bucal e lesões de tecidos moles na população dos Estados Unidos, FISCHMAN (1985) analisou tanto a incidência e prevalência dos tumores relacionados à cavidade bucal, quanto as condições associadas a seu tratamento. Ao comentar os dados do programa "Surveillance, Epidemiology, and End Results" (SEER), conduzido pelo Instituto Nacional do Câncer daquele país, o autor relatou que a incidência anual de câncer bucal e de faringe (definidos pela nona revisão da Classificação 
Internacional de Doenças sob os códigos 140 a 148) foi de 11,2 casos por 100.000 pessoas, onde a incidência para homens foi de 17,4 por 100.000 , e para mulheres, 6,2. Com relação à mortalidade, FISCHMAN (1985) descreve que o coeficiente global observado nos Estados Unidos foi de 3,4 por 100.000 habitantes, sendo 5,9 por 100.000 para homens e 1,9 por 100.000 para mulheres. Com relação à tendência de óbitos, o autor relatou decréscimo entre os períodos $1937-39$ e $1969-71$, de 15,1 por 100.000 para 10,1 por 100.000 habitantes, provavelmente devido à diminuição da incidência de câncer de lábio. Desse modo, observou-se diminuição das taxas de mortalidade ajustadas por idade para as localizações anatômicas com melhor prognóstico, e um incremento relativo dos tipos de câncer, como o de língua, que possuem prognóstico desfavorável (FISCHMAN, 1985). FISCHMAN (1985) comenta ainda que o aumento da incidência do câncer bucal, associado ao aumento da longevidade desses pacientes faz com que ocorra uma maior quantidade de pacientes que demandam o uso dos serviços de saúde.

Ao comentar que a maioria dos cânceres de boca são precedidos por lesões cancerizáveis, GUPTA et al. (1986) explicam que a educação em relação ao uso do tabaco seria uma alternativa plausível e efetiva para a prevenção primária do câncer bucal. Os autores comentam diversos estudos realizados na Índia onde se encontrou alta prevalência de câncer bucal, sempre associada ao hábito do uso do tabaco, seja consumido por meio de fumo, seja mastigado. GUPTA et al. (1986) conduziram um estudo em três distritos da Índia (Distrito de Ernakulam, em Kerala, Distrito de Srikakulam, 
em Andhra Pradesh e Distrito de Bhavnagar, em Gujarat). Duas coortes distintas foram selecionadas em cada distrito e seguidas em intervalos regulares por 10 anos, por meio de entrevista e exame clínico, em seguimento domiciliar. As entrevistas tinham como objetivo levantar o hábito do uso do tabaco, e o exame clínico documentava toda e qualquer lesão cancerizável, inclusive com fotografias coloridas. A totalidade da população com mais de 15 anos de idade e usuária de tabaco de cada vila selecionada foi rastreada, perfazendo mais de 12.000 participantes em cada distrito. Foram excluídos apenas os residentes temporários, pessoas doentes, pessoas com perturbações psicológicas, e pessoas que já haviam passado por tratamento relacionado a câncer bucal. Os participantes portadores de lesões de mucosa bucal não eram informados sobre sua presença. Após o exame clínico realizado pelo dentista, um cientista social oferecia informação ao examinando sobre o uso de tabaco por meio de filmes, pôsters e artigos. Os exames foram inicialmente realizados em 1966 e 1967, e novamente após 3 anos, e mais uma vez a cada ano seguintes, totalizando o seguimento de 10 anos. Os autores obtiveram uma taxa de $97 \%$ de participantes seguidos até o final do estudo, sendo que a incidência de leucoplasia ajustada por idade num período de 5 anos foi, no Distrito de Ernakulam, de 11,4 no grupo que sofreu intervenção (atividades educativas) versus 47,8 entre homens, e 5,8 versus 33,0 entre as mulheres por 1000 habitantes; no Distrito de Srikakulam, encontraram lesões no palato em 59,8 versus 260,8 por 1000 habitantes entre os homens e 289,5 versus 489,5 entre as mulheres. E, finalmente, no Distrito de Bhavnagar, a taxa de leucoplasia não variou entre as coortes. Os achados se mostraram 
estreitamente relacionados com a redução do consumo de tabaco observada no período de estudo, sendo significantemente maior no Distrito de Ernakulam, e bastante inferior no último distrito citado (GUPTA et al., 1986).

Em um breve relato sobre leucoplasia e incidência de câncer bucal, GUPTA (1989) comenta que a incidência de câncer bucal é muito maior na Índia do que no Norte da Europa; por outro lado, tanto a prevalência quanto a transformação maligna de uma das mais importantes lesões cancerizáveis, a leucoplasia bucal, têm sido muito menos relatadas da Índia do que dos paises do Norte da Europa. O autor sugere que tal achado possa ser explicado pelo fato de que as amostras indús não têm sido constituídas de populações pré-selecionadas, ao passo que nos países europeus ocidentais têm sido baseadas em informações de base hospitalar.

SMITH et al. (1990), em trabalho de revisão que teve como objetivo discutir os aspectos epidemiológicos da ocorrência de câncer bucal por todo o mundo, chamam a atenção para o fato de que em muitos trabalhos publicados, cânceres de língua, gengiva e partes não especificadas da cavidade bucal são analisados juntamente com cânceres da orofaringe e hipofaringe. Assim, tal agrupamento pode trazer vantagens, tais como diminuição de problemas de classificação dos tipos de câncer, bem como desvantagens, tais como perdas de informações detalhadas decorrentes de diferenças biológicas e epidemiológicas dos diferentes tipos de câncer em estudo (SMITH et al., 1990).

Ao resumir um relato da Federação Dentária Internacional (FDI) a respeito da etiologia, dos fatores de risco e da necessidade de futuras 
pesquisas a respeito das neoplasias bucais, JOHNSON (1991) destacou que nos paises em desenvolvimento, as neoplasias bucais e de faringe ocupam o $3^{0}$ lugar entre a ocorrência de neoplasias malignas nas populações. Enfatiza também a necessidade de formatos de pesquisas que possibilitem comparações de dados entre os paises, destacando que, em alguns trabalhos, não é possivel a identificação, de forma separada, entre a ocorrência de neoplasias malignas da cavidade bucal e da nasofaringe.

No Estado de Connecticut, Estados Unidos, foi realizado um estudo epidemiológico com o objetivo de analisar os padrões demográficos e de distribuição do câncer bucal, entre 1935 e 1985 (CHEN et al., 1991). As fontes investigadas foram o Registro de Tumores do Connecticut (CTR) e o Serviço de Biópsia e Patologia Bucal do mesmo Estado. Os autores observaram que, durante o período de estudo, 9.708 casos foram relatados ao CTR; as taxas ajustadas de câncer bucal para homens permaneceram estáveis entre 1935 e 1964 (14,5 a 14,8 por 100.000 habitantes), com um declínio gradual para 10,9 no início dos anos 80 . Em contraste, as taxas ajustadas por idade para as mulheres triplicaram, de 1,4 nos anos 30 para 4,1 no início dos anos 80 (para as idades entre 40 e 79 anos). Observaram um decréscimo de taxas em idades especificas para o câncer entre os homens com idades de 70 anos e mais, ao passo que para as mulheres, nessa mesma faixa etária, as taxas permaneceram estáveis.

GUPTA et al. (1992) estudaram duas coortes em levantamentos realizados a respeito de consumo de tabaco e lesões cancerizáveis, durante 10 anos, entre 12.212 usuários de tabaco no Estado de Kerala, Índia. Essas 
pessoas receberam orientações contínuas desencorajando o uso constante destes produtos; o outro grupo era formado por 6.075 usuários de tabaco, que receberam aconselhamento mínimo a respeito da descontinuidade de seu uso. Encontraram que houve uma redução do uso de tabaco, e da incidência de leucoplasia no primeiro grupo, quando comparado com o grupo controle. Os autores concluíram que existe a possibilidade real de se executar prevenção primária relacionada ao câncer bucal.

Ao compilar diversos estudos para analisar a prevalência das lesões da mucosa bucal em todo o mundo, KLEINMAN et al. (1993) evidenciaram que existe ampla variação entre regiões geográficas, localizações anatômicas e gênero. Na maioria das populações, os homens tiveram taxas maiores de ocorrência que as mulheres em todos as localizações anatômicas. Para a maioria destes locais anatômicos, as taxas de incidência permaneceram constantes ou declinaram um pouco durante os períodos cobertos, porém incrementos foram notados em alguns países e localizações anatômicas. A mudança mais notável foi um decréscimo no câncer de lábio nos Estados Unidos entre 1976 e 1987. Uma diminuição na prevalência do câncer de língua em homens foi aparente em Bombaim, Índia, entre 1970 a 1987.

Um estudo retrospectivo analisou se fatores como sexo e raça influenciaram a sobrevivência de 4527 pacientes que procuraram por atendimento no Hospital A. C. Camargo, São Paulo, Brasil, entre 1953 e 1980 (FRANCO et al., 1993). Foram incluídos no estudo todos os casos de tumores epiteliais da boca, códigos $140,141,143,144$ e 145 da $9^{a}$. revisão 
da Classificação Internacional de Doenças, com exceção dos tumores de glândulas salivares (código 142). Todos os diagnósticos foram confirmados histopatologicamente. Os autores observaram que o estadiamento do tumor correspondeu a um fator muito mais relevante na sobrevivência do paciente do que as variáveis supra-citadas. FRANCO et al. (1993) encontraram a seguinte distribuição de localizações anatômicas no estudo: lábio (40,8\%), língua (20,8\%), gengiva $(5,7 \%)$, assoalho bucal $(16,7 \%)$, e outras partes da boca (16\%). Homens foram mais acometidos que mulheres, na proporção de 6:1. Diferenças raciais relacionadas ao estadiamento e tratamento mereceram maior destaque que sexo, já que o estudo encontrou que negros e mulatos tenderam a possuir tumores em estágio muito mais avançado no momento do diagnóstico. Dentre os fatores que poderiam ser citados como importantes relacionados à decisão do paciente em procurar por atendimento, os autores destacaram sexo, raça, além de fatores socioeconômicos e culturais.

Ao levantar a mortalidade por câncer bucal no Estado de São Paulo segundo sexo, idade, localização do tumor e região administrativa entre 1979 e 1982, NEVES (1994) encontrou que os óbitos por câncer bucal no Estado corresponderam a 2,1\% do total de óbitos por câncer no período. $O$ material estudado foi o de registros de óbito do Ministério da Saúde, em que a causa básica de óbito foi o câncer de boca. O litoral paulista e o vale do Paraiba apresentaram os maiores coeficientes de mortalidade: 2,16 e 1,83 por 100.000 habitantes, respectivamente. Os óbitos por câncer de língua foram os mais prevalentes no período, e os de lábio e gengiva, os que 
apresentaram menor ocorrência.

MACFARLANE et al. (1996) realizaram uma análise de sobrevivência a partir de dados obtidos do registro nacional de câncer escocês, no período de 1968-87. Tinham como objetivo determinar se, nesse periodo, houve mudanças na tendência de sobrevivência, bem como levantar quais fatores específicos poderiam ser atribuídos aos achados. Encontraram, no período de 1968 a 1972, em 47\% dos portadores de câncer de língua, boca e faringe, com idades inferiores a 65 anos, taxas de 5 anos de sobrevida; esta porcentagem, no período de 1983 a 1987, caiu para 39\%. Para pessoas mais idosas, observou-se uma melhoria modesta, de $34 \%$ para $38 \%$ a taxa de sobrevida. Ao considerar-se o grau de privação social, a taxa de sobrevivência foi menor entre os indivíduos provenientes de áreas menos favorecidas, e, segundo os autores, é em tal grupo que os incrementos na ocorrência de câncer da cavidade bucal e da faringe têm ocorrido.

SWANGO (1996), com o objetivo de estudar a magnitude do problema de saúde pública reapresentado pelos cânceres de boca e de faringe, e observar tendências na incidência, mortalidade e sobrevivência, reviu dados epidemiológicos americanos, a partir das informações publicadas em fontes nacionais de dados sobre incidência e mortalidade pelo agravo: Instituto Nacional do Câncer ( $\mathrm{NCl}$ ), programa "Surveillance, Epidemiology, and End Results" (SEER), e Centro Nacional de Estatística de Saúde (NCHS). As fontes citadas somente forneceram dados detalhados para idade, sexo e raça para câncer de boca e de faringe, num mesmo grupo. O autor concluiu que mudanças demográficas, como o 
envelhecimento da população, iriam provocar grande influência na epidemiologia do câncer bucal e da faringe nas décadas seguintes, e que para os idosos americanos, estes tipos de câncer deverão se tornar um problema crescente.

O'HANLON et al. (1997) relataram a incidência e a mortalidade por câncer bucal no Noroeste da Inglaterra, entre 1971 e o início dos anos 90. Nesse trabalho, verificaram a totalidade dos dados de registro de câncer para a região, associando tais dados à privação material e testaram a cobertura dos dados de registro de câncer. Encontraram que, para os homens, para câncer de língua e o da cavidade bucal (CID-9 códigos 143145), houve um aumento gradual nos registros padronizados, tanto para as áreas mais ricas quanto para as menos favorecidas, sendo que tais diferenças se mostraram menos evidentes em mulheres. Encontraram também diferenças na incidência de câncer bucal entre Inglaterra e País de Gales e a Região Noroeste da ilha, devido, provavelmente, a diferentes estilos de vida entre as comunidades estudadas. Esta última região apresentou pior condição que as outras em uma série de itens relacionados à privação material.

Em artigo de revisão, WINN et al. (1998) listam uma série de iniciativas do governo americano, tanto em âmbito federal quanto local, que têm sido implementadas com o intuito de reduzir a mortalidade por câncer bucal no país. Os autores explicam que os números absolutos da mortalidade por câncer bucal vêm aumentando, destacando-se a Califórnia, Estado este que concentra o maior número de habitantes dos Estados 
Unidos. Ainda falando a respeito desse Estado, destacam o grande número de descendentes de chineses que lá habitam, etnia esta mais constante da presença de câncer de boca. Outra questão levantada pelos autores se refere ao fato de que a maior parte dos cirurgiões-dentistas americanos não examina rotineiramente seus pacientes adultos com o intuito de pesquisar lesões na cavidade bucal.

Nos Estados Unidos, houve maior quantidade de cânceres de todos os tipos em 1997 que em 1988, mas o número de novos casos de câncer bucal tem crescido apenas timidamente, já que eles constituíram $2,2 \%$ de todos os novos casos relatados em 1997 , e $3,8 \%$ dos casos relatados em 1988 (BURT e EKLUND, 1999). A mortalidade por câncer de boca tem também diminuido, tanto em números absolutos quanto proporcionalmente, e, em 1997, foi responsável por 1,5\% de todos os óbitos por câncer (BURT e EKLUND, 1999).

Sabendo que a mortalidade por câncer de boca e de faringe é bastante inferior entre homens japoneses do que entre homens de outros países desenvolvidos (3,5 por 100.000 no Japão entre 1983 e 1987, e, no mesmo período, 15,0, 15,6, 11,1 e 14,5 na França, Hong Kong, Hungria e Singapura), SU et al. (1999) fizeram uma análise de tendência de óbitos por câncer bucal e de faringe por localização anatômica específica e também global entre homens japoneses, no período de 1950 a 1994, por meio das informações obtidas pelos censos nacionais e estatísticas de mortalidade rotineiramente publicados pelo Ministério da Saúde e do Bem-Estar do Japão. A proporção de óbitos por câncer de boca e de faringe entre o total 
de mortes diminuiu de $1,24 \%$ em 1950 para 0,91 em 1966, mas a partir daí, aumentou continuamente, atingindo $1,60 \%$ em 1994. A taxa ajustada de mortalidade aumentou de 1,95 por 100.000 no período de $1950-54$ para 3,30 por 100.000 em 1990-94 (SU et al., 1999). A mortalidade por câncer de lábio, cavidade bucal e faringe aumentou consistentemente durante o período de estudo, com ascensão semelhante ao se analisar localizações anatômicas específicas da cavidade bucal.

MORSE et al. (1999) analisaram as tendências de ocorrência de câncer de lábio, de cavidade bucal e de faringe no Estado de Connecticut, Estados Unidos, entre 1935 e 1994. Foi utilizada a Classificação Internacional de Doenças para a Oncologia, na sua segunda edição, e casos registrados em versões anteriores foram recodificados pelos pesquisadores segundo essa versão. Estimativas populacionais por idade e sexo foram baseadas nos Censos Populacionais do Estado do Connecticut (para o periodo de 1935 a 1979) e Censo dos Estados Unidos (para o periodo de 1980 a 1994). Houve, de 1935 a 1994, um total de 16.252 casos de câncer de lábio, bucal e de faringe (MORSE et al., 1999). Pelo fato de já ter sido realizado levantamento prévio do período entre 1935 e 1985 (CHEN et al., 1991), os autores deram maior ênfase às informações obtidas para a década dos anos 90 . Encontraram decréscimo de $24 \%$ das taxas para o câncer de lábio (ajustadas por idade) para o período como um todo; o câncer bucal por idade específica passou por um pico no início dos anos 60 e ao final dos 70 , ao passo que as taxas de câncer de faringe aumentaram ao final dos anos 70. Para cada uma das localizações anatômicas anteriormente citadas, as 
taxas começaram a declinar em 1980-1984, e continuaram em declínio na primeira metade dos anos 90 . Ao contrário do observado no período de 1935-1984, as taxas ajustadas por idade para o câncer bucal e de faringe caíram nos últimos 10 anos do estudo.

PINTO (1999), em trabalho de revisão sobre a possibilidade de intervenções preventivas para o câncer bucal, relata que há distinta prevalência de localizações anatômicas para o câncer bucal entre homens e mulheres, com uma maior presença nestas de lesões de glândulas salivares e gengivais. Destaca também o efeito sinérgico da associação do uso do tabaco e álcool em relação ao risco de desenvolvimento de lesões cancerizáveis e câncer bucal.

Em artigo de revisão que compilou a incidência de câncer bucal em todo o mundo (CID-9, códigos 143 a 145), MOORE et al. (2000) encontraram variações geográficas significativas na incidência de câncer bucal, com altas taxas relatadas para o subcontinente indiano, e partes da Ásia (mais de 10 por 100.000 habitantes ao ano). Além disso, os autores observaram ausência de dados confiáveis provenientes de países em desenvolvimento.

JITOMIRSKI (2000) destaca que "por sua elevada letalidade e possibilidade de identificação precoce por parte da rede básica de atendimento odontológico, o câncer bucal constitui um problema de saúde pública (...) prioritário". A autora comenta também que o diagnóstico precoce não tem sido realizado, já que grande parte dos pacientes são atendidos quando em estágio avançado da lesão. 
OLIVEIRA e ODELL (2000) explicam que as informações epidemiológicas mais completas obtidas em relação à incidência e mortalidade por câncer bucal são originadas em partes do mundo com altas taxas de incidência da doença. Os autores comentam também que no Brasil, - câncer permanece como a terceira causa de morte, sendo maior a prevalência em órgãos tais como mama, próstata e cólon.

ANTUNES et al. (2001) avaliaram os dados de mortalidade de câncer bucal no município de São Paulo para estudar as tendências da doença e sua distribuição por áreas da cidade. Padronizaram as taxas de mortalidade por sexo e faixa etária, e encontraram que a mortalidade por câncer bucal permaneceu estacionária em níveis altos entre 1980 e 1998. As taxas de morte por local específico revelaram tendência ascendente para uma das categorias de localização: partes não especificadas da cavidade bucal. Os autores sugerem que tal resultado pode indicar demora em relação ao diagnóstico e ao estabelecimento de medidas terapêuticas adequadas.

MIRRA et al. (2001), ao levantar a incidência de câncer no Município de São Paulo nos anos de 1997 e 1998, explicam que o Registro de Câncer de São Paulo cataloga o número de casos de câncer e não o de pacientes. Assim, pode haver maior número de casos do que pessoas, já que uma mesma pessoa pode ser portadora de mais de um tipo de câncer.

Em documento que estima as incidência e mortalidade por câncer no Brasil em 2002, o Instituto Nacional do Câncer (INCA, 2002) relata que, para câncer de boca no município de São Paulo, a estimativa foi de 980 casos novos (taxa bruta de 19,07 por 100.000 habitantes) na capital entre homens, 
e 390 (taxa bruta de 6,88) por 100.000 habitantes entre mulheres; com relação aos óbitos para 2002, a capital contou com uma taxa bruta de 5,71 para homens e 1,36 para mulheres, por 100.000 habitantes.

\subsection{Iniqüidade e saúde}

Segundo FERREIRA (1999), desigualdade corresponde ao "estado do que é desigual" e disparidade, à "qualidade do que é díspar"; eqüidade, por sua vez, refere-se à "1) disposição de reconhecer igualmente o direito de cada um. 2) conjunto de princípios imutáveis de justiça que induzem o juiz a um critério de moderação e de igualdade, ainda que em detrimento do direito objetivo", e finalmente, iniqüidade, como "falta de eqüidade".

A eqüidade em saúde tem sido conceituada de diversos modos. Em geral, as suas definições têm em comum a idéia de que certas diferenças em saúde (inequalities) são injustas. Assim, o subgrupo de iniqüidades (falta de eqüidade, ou inequalities) que são consideradas injustas têm sido chamadas de inequities em saúde (MACINKO e STARFIELD, 2002).

WHITEHEAD (1985) explica que inequality em saúde é um termo "comumente usado em alguns países para indicar diferenças sistemáticas, evitáveis e importantes. Entretanto, há alguma ambigüidade sobre o termo (...). Somado a isso está o problema de tradução em alguns idiomas, onde há somente uma palavra disponivel para cobrir inequality e inequity..."

BLOOM (2000) explica que o conceito de "eqüidade" constitui uma "afirmação da natureza moralmente inaceitável de certas iniqüidades no acesso a benefícios sociais". Destaca também que a equação de falta de 
eqüidade politicamente relevante com medidas absolutas de falta de eqüidade de acesso e/ou resultados de saúde devem ser considerados ao mensurar a iniqüidade.

DACHS (2001) explica que "inequidad es lo opuesto de la equidad, pero no es la iniquidad que significa simplemente injusticia". Destaca que se trata de um problema ético, e que deve ser discutido desde o ponto de vista da justiça.

WILKINSON (1996) explica que entre os paises desenvolvidos, a melhor saúde ocorre não naqueles mais ricos, mas sim naqueles que possuem as menores diferenças de rendimentos entre ricos e pobres. $O$ autor acrescenta que iniqüidade e pobreza relativa possuem efeitos absolutos: eles aumentam as taxas de mortalidade", e as variáveis de assistência médica acabam por ocupar um papel secundário nesse quadro (WILKINSON, 1996).

SPOSATI (1996) elaborou um compêndio de índices, tanto relacionados à exclusão social quanto discrepância interdistrital nos 96 distritos que formam o Município de São Paulo. Para a autora,

"o conceito de eqüidade é concebido como o reconhecimento e a efetivação, com igualdade, dos direitos da população, sem restringir 0 acesso a eles nem estigmatizar as diferenças que conformam os diversos segmentos que a compõem. Assim, a eqüidade é entendida como:

- possibilidade das diferenças serem manifestadas e 
respeitadas, sem discriminação;

- condição que favoreça o combate das práticas de subordinação ou de preconceito em relação às diferenças de gênero, políticas, étnicas, religiosas, culturais, de minorias etc."

GOLDBAUM (1997) explica que ao longo dos anos, tem-se procurado uma série de explicações para esclarecer as diferenças na ocorrência de situações de saúde em populações, com destaque para os estudos que citam os diferenciais de adoecimento nos diversos grupos sociais.

MORRIS (1997) destaca que a mortalidade por todas as causas, nos Estados Unidos, está relacionada com a renda dos $50 \%$ mais pobres.

PEARCE (1997) comenta que tem sido encontrada forte associação entre classe social e câncer em grande parte dos países industrializados, explicando que "a forma como o PIB (Produto Interno Bruto) é 'repartido' revela-se tão importante quanto seu nivel absoluto" para a ocorrência de diversas doenças, incluindo o câncer.

LAURELL (1997), ao comentar o impacto das políticas sociais e econômicas na morbi-mortalidade das populações, destaca que a ausência dos elementos de consumo básico é a situação limite que afeta os países e a população mais pobre para o risco de adoecer; a autora destaca também os transtornos da saúde causada pela perda de inserção na produção em uma sociedade produtivista.

WILKINSON (1997), ao realizar uma análise da relação internacional 
entre eqüidade de renda e expectativa de vida, explica que vários estudos vêm demonstrando que, independente do grau de desenvolvimento do país, as populações que apresentam menores diferenças de renda entre seus diversos segmentos tendem a usufruir melhor saúde.

CASTELLANOS (1997), ao analisar os perfis de mortalidade, nível de desenvolvimento e iniqüidades sociais na região das Américas, concluiu que todos os países obtiveram, nos últimos 30 anos, reduções significativas nas taxas de mortalidade. $\mathrm{O}$ autor acrescenta que

"estes ganhos, no entanto, não foram semelhantes em todos os países nem em todos os grupos de população, mantendo-se brechas redutiveis de mortalidade (BRM) em quase todos os grupos de idade abaixo dos 65 anos de idade. Estas BRM tendem a ser maiores na medida em que é menor o nível de desenvolvimento econômico dos países, evidenciandose assim a relação sinérgica, de impacto mútuo favorável, entre crescimento econômico e situação de saúde" (CASTELLANOS, 1997, p.148).

Ao destacar a relevância de se estudar perfis de mortalidade segundo aspectos geográficos e sociodemográficos, BARROS (1997) destaca estudo realizado em Campinas, onde o Município foi dividido em 4 conglomerados segundo o local de residência, para mensurar a mortalidade em tais localidades, bem como a cobertura dos serviços de saúde oferecidos à população. Encontrou coeficientes de mortalidade maiores para as regiões 
menos favorecidas, independente da causa do óbito - doença cardiovascular, causas externas, doença infecto-parasitária ou homicídios.

MONTEIRO (1997), ao analisar os efeitos da transição demográfica sobre a saúde da população no Brasil, explica que as doenças infecciosas e parasitárias (ainda que facilmente evitáveis), são responsáveis por cerca de $15 \%$ da mortalidade nas Regiões Norte e Nordeste, ao passo que nas Regiões Sul e Sudeste, essa proporção, em 1990, era de menos de 5\%. Destaca que nessas duas últimas regiões, as neoplasias e as doenças circulatórias são responsáveis por aproximadamente metade dos óbitos.

Segundo CASAS (1999), a Organização Pan-Americana da Saúde (OPAS) define iniqüidades em saúde como "aquelas disparidades (...) que são claramente injustas, desnecessárias e evitáveis e com relação às quais um agente responsável, geralmente o setor público em colaboração com o setor privado e a sociedade civil, pode intervir para reduzir ou compensar estas diferenças". O autor acrescenta que é responsabilidade do setor saúde a identificação destas iniqüidades, bem como o estabelecimento de estratégias para sua redução.

MARMOT (1999) afirma que quando as pessoas mudam de ambiente, seus padrões de risco à doença também são modificados. Mas defeitos no sistema de assistência médica não são a causa dos problemas, afirma o autor, e levanta a seguinte questão:

"estamos errados ao concluir que o ambiente em que a pessoa vive, o ambiente de trabalho, o desemprego, os 
padrões de relações sociais, a exclusão social, alimentação, comportamento e transporte estão relacionados com a relação causal saúde-doença quando, na verdade, estas relações aparentes poderiam ser todas atribuídas à falta de acesso a assistência médica de boa qualidade? Claramente,não acreditamos que essas relações sejam causais e que sejam determinantes de diferenças nas taxas de doença numa mesma ou entre sociedades. Elas criam problemas com os quais o sistema de assistência deve competir. Defeitos nos sistemas de serviços de saúde não serão a causa do problema" (MARMOT, 1999, p.3)

O uso de drogas, e álcool e de cigarro correspondem a comportamentos individuais que envolvem um elemento de escolha pessoal, e a persistência de comportamentos não saudáveis é, em diversas ocasiões, vista simplesmente como uma fraqueza, mais do que uma reação a circunstâncias sociais (JARVIS e WARDLE, 1999). Os autores explicam ainda que no Reino Unido, os óbitos causados pelo tabaco têm diminuído mais nos grupos que experimentam melhores condições materiais do que em grupos com maior experiência de privação social.

WATT E SHEIHAM (1999) procuraram esclarecer as evidências existentes na associação entre saúde bucal e iniqüidade social, comentando que, embora a saúde bucal tenha melhorado de forma acentuada nos últimos 20 anos, as iniqüidades em saúde bucal vêm se ampliando. Os 
autores explicam que, na Inglaterra, o câncer bucal localizado tanto na língua quanto na boca, em homens, tem mostrado um aumento gradual em sua ocorrência e mortalidade, das áreas mais ricas para as mais pobres.

Em uma reflexão crítica sobre iniqüidades em saúde e a saúde dos pobres, GWATKIN (2000) destaca os diferentes aspectos da saúde que têm sido considerados quando o tema citado é discutido: alguns autores o abordam em relação às condições de saúde, utilizando-se de temas tais como a mortalidade infantil e a expectativa de vida; outros, por meio de uso e financiamento dos serviços, analisando-se a procura e pagamento de serviços de saúde por indivíduos; outros autores ainda o fazem observando o modo em que grupos econômicos obtém financiamento governamental para gastos com serviços curativos de saúde.

GAKIDOU et al. (2000) afirmam que tem sido observado, nos últimos anos, um aumento no consenso de que a melhoria dos níveis de saúde não constitui um indicador suficiente para a avaliação do funcionamento do sistema de saúde de uma comunidade. Além disso, os autores explicam que, ao situar as iniqüidades dentro do debate das políticas de saúde, métodos de mensuração mais eficazes devem ser desenvolvidos, permitindo-se, assim, a determinação da verdadeira magnitude do problema e melhor monitoramento dos progressos já realizados.

LOCKER (2000) comenta que a associação entre a condição socioeconômica e a saúde, incluindo saúde bucal, está bem estabelecida, e que as medidas convencionais de condições socioeconômicas usadas em diversos estudos, tais como classe social e rendimento familiar, possuem 
limitações. Assim, medidas baseadas em áreas de pobreza suplementam, mais do que substituem, tais medidas convencionais (LOCKER, 2000).

MINAYO (2000) explica que "quando falamos de desigualdades, estamos nos referindo às distâncias relativas (freqüentemente extremas) que existem entre os estratos populacionais, na apropriação não somente econômica, mas também dos bens, serviços e direitos sociais, políticos e culturais de um país, ou entre países, (...)." A autora destaca também que pelo fato de estabelecer uma possibilidade comparativa, o conceito de desigualdade é relativo.

Dentre os instrumentos existentes para superar as dificuldades relacionadas à identificação e redução das desigualdades sob o aspecto da eqüidade e planejamento na gestão do Sistema Único de Saúde, LUCCHESE (2000) destaca a

"valorização da epidemiologia (grifo no original) como conhecimento científico imprescindível para a compreensão dos determinantes e riscos que condicionam o processo saúde/doença; como conjunto de métodos e técnicas relevantes para a identificação dos reais problemas $e$ necessidades que afligem a população; e como suporte básico ao planejamento, administração e avaliação do impacto das ações e serviços sobre as diferentes realidades de saúde local (...)" (LUCCHESE, 2000) 
A evolução dos indicadores relacionados com a saúde e condições de vida têm melhorado no Brasil, nos últimos dez anos, mas a proporção da população com menos de quatro anos de escolaridade ainda é alta no país (VIANNA et al., 2001).

PATTUSSI et al. (2001) realizaram um estudo ecológico para investigar as possíveis associações entre privação social, desigualdade de renda e coesão social com os níveis de cárie dentária de escolares do Distrito Federal. Os autores concluíram que os níveis de renda foram os determinantes mais fortes do ataque de cárie encontrados no estudo.

BARROS et al. (2001), ao explicar que o Brasil é o país com o maior grau de desigualdade entre os analisados por avaliação do Instituto de Pesquisa Econômica Aplicada (IPEA), mostra que a renda média dos $10 \%$ mais ricos representa 28 vezes a renda média dos $40 \%$ mais pobres. Concluem que "apesar da evidente importância da redistribuição de renda para o combate à pobreza no brasil, os únicos mecanismos utilizados para reduzir a pobreza, além de extremamente limitados quanto ao seu impacto, resultam, de modo sistemático, do crescimento econômico."

STARFIELD (2002), ao discutir a não aleatorização da distribuição de saúde em populações, explica que "algumas pessoas e alguns grupos dentro da população experimentam mais do que a justa distribuição de saúde e doença, e algumas menos", e que pouco dessa distribuição poderia ser atribuída à genética. 
ESCOREL (2002) destaca que

"há uma tendência na bibliografia de tentar definir eqüidade diferenciando-a da igualdade. Os argumentos centram-se que igualdade é um princípio de justiça social, aborda a ética dos arranjos sociais, têm conteúdos francamente valorativos e está centrada nos direitos de cidadania. Mas esses argumentos não permitem distinguir da eqüidade que também incorpora regras de distribuição justas, encerra juízos de valor e é regida pelas orientações filosófico-políticas que regulamentam a vida social. Ambos conceitos, igualdade e eqüidade, partem do princípio que a humanidade é diversa, plural, que os seres humanos diferem entre si em suas personalidades, identidades e necessidades.

As desigualdades serão consideradas justas ou injustas conforme as distintas interpretações sobre os processos sociais determinantes da estratificação social." (ESCOREL, 2002)

A Declaração de Toronto de Eqüidade em Saúde, documento elaborado pela Sociedade Internacional para a Eqüidade em Saúde (ISEqH, 2002), explica que: 
"A eqüidade em saúde é construída sob a condição de que as pessoas tenham acesso a recursos, capacidades e poder de que necessitam para agir sobre as circunstâncias de suas vidas que determinam sua saúde. (...)

Eqüidade nos resultados de saúde deve ser um objetivo central dos profissionais de saúde, cidadãos e seus governantes. (...)

Iniqüidades no acesso e resultados não estão restritos a qualquer sistema de atenção à saúde ou econômico. (...)

A expansão do setor privado no curso da globalização do comércio e finanças tem sido associada com o crescimento das iniqüidades na saúde entre países e dentro de países. (...)

Os direitos humanos são centrais para a eqüidade em saúde. (...)" (ISEqH, 2002).

\subsection{Agregados domiciliares e condição socioeconômica}

PANACHÃO (1995) estudou a distribuição espacial da mortalidade por câncer ginecológico no Município de São Paulo no ano de 1992, dividindo o município em 4 zonas homogêneas a partir de critérios 
socioambientais. Assim, a cidade foi dividida em 4 zonas, levando-se em consideração a média de renda per capita, porcentagem de analfabetismo e pessoas com o primário incompleto, porcentagem de casas ligadas à rede de esgoto, média per capita de consumo de água e número de habitantes por residência. Encontrou que o câncer de mama foi o que apresentou coeficientes de mortalidade mais elevados em todo o município, seguindo-se de câncer de colo uterino e ovário. O estudo explica que embora o coeficiente de mortalidade por câncer ginecológico tenha sido maior nas áreas com melhores condições de vida, ao calcular-se os anos potenciais de vida perdidos, estas áreas apresentaram menores resultados.

JONES et al. (1997), ao executar um estudo ecológico na GrãBretanha para analisar os efeitos da fluoretação natural e artificial da água em 3 regiões em crianças de 5 anos de idade, encontraram que, quanto menos privilegiada a área estudada, maior o benefício experimentado pela população que teve a oportunidade de receber o flúor e menor a experiência de cárie da população. Os autores utilizaram o escore de Jarman relacionado a áreas pouco privilegiadas como um indicador de privação social, explorando-o para observar sua possivel relação com a cárie dentária. Tal escore é utilizado pelo Ministério da Saúde do Reino Unido para planejamento de captação de recursos para pagamento dos médicos clínicos gerais do país.

Ao descrever o padrão de mortalidade por câncer de próstata no Estado do Rio Grande do Sul entre 1970 e 1992, FARDO (1999) utilizou-se de divisão do estado em mesorregiões. Encontrou que os coeficientes de 
mortalidade foram maiores no Sul do Estado: Sudeste e Sudoeste RioGrandense. As Regiões que apresentaram menores coeficientes foram a Mesorregião Nordeste, Noroeste e Centro-Oriental. Uma das possibilidades relacionadas a esse achado pode ser o fato de que a Região Sul do Estado possui, culturalmente, hábitos diferentes dos habitantes das outras regiões. No primeiro caso, hábitos alimentares diferentes, decorrentes do estilo de vida da população local, residente em latifúndios e consumindo grande quantidade de carnes vermelhas e chimarrão, poderiam estar associados ao fato de se ter encontrado um coeficiente de mortalidade por câncer de próstata superior que para as Regiões Nordeste, Noroeste e Centro-Oriental. O autor acrescenta ainda que diversas pesquisas sugerem estreita relação entre hábitos dietéticos e prevalência de câncer de próstata.

Ao estudar a distribuição espacial da mortalidade por câncer de mama segundo 63 Microrregiões do Estado de São Paulo entre os anos 1991 e 1995, GOMES (2000) observou que, menores coeficientes padronizados de mortalidade foram encontrados em Microrregiões de pequenas densidades populacionais e os valores altos foram geralmente observados em grandes concentrações populacionais. $O$ autor atribui tal achado ao fato de que a mortalidade tende a se concentrar em regiões com maior taxa de urbanização.

SANTOS et al. (2000) explicam que "uma das maneiras de se conhecer mais detalhadamente as condições de saúde da população é através de mapas que permitam observar a distribuição espacial de situações de risco e dos problemas de saúde, (...) (permitindo) a integração 
de dados demográficos, socioeconômicos e ambientais, promovendo o interrelacionamento das informações de diversos bancos de dados" (p.13).

ZANATTA (2001) estudou a mortalidade por câncer de mama entre as mulheres residentes no Estado de Santa Catarina no período de 1979 a 1997. Utilizou a divisão do estado nas 6 Mesorregiões geográficas utilizadas pelo Instituto Brasileiro de Geografia e Estatística (IBGE): Oeste Catarinense, Norte Catarinense, Serrana, Vale do Itajaí, Grande Florianópolis e Sul Catarinense. A análise dos coeficientes de mortalidade mostrou-se crescente no período, principalmente para a região da Grande Florianópolis. A análise contemplou tanto local de residência quanto de ocorrência do óbito.

REIS (2001) realizou um estudo para investigar a relação da mortalidade por neoplasias malignas $e$ as diferentes inserções socioeconômicas da população no Município de São Paulo em 1997. Encontrou associações positivas e estatisticamente significativas entre razão de mortalidade padronizada em áreas mais privilegiadas (definidas por meio de uma série de variáveis de exclusão social, segundo classificação elaborada por SPOSATI, em 1996) para câncer de mama (para o sexo feminino), pulmão (para o sexo masculino) e câncer de cólon para ambos os sexos. O autor destaca que os achados da pesquisa indicam a existência de diferenças de risco para mortalidade por alguns tipos de câncer segundo o grau de inserção econômica na população do Município de São Paulo.

BALDANI et al. (2002), em análise das relações entre cárie dentária e fatores socioeconômicos no Estado do Paraná, encontraram correlação 
significativa entre a doença supra-citada e indicadores de desenvolvimento social, tais como condições de saúde, renda, moradia, educação, índice de desenvolvimento humano, índice de condições de vida, índice de salubridade e índice de desenvolvimento infantil.

ANTUNES et al. (2002) analisaram a associação entre cárie dentária e necessidades de tratamento em escolares de São Paulo e indicadores de desenvolvimento social baseados em diversas áreas do Município. Os escolares residentes nas regiões centrais foram menos afetados pela cárie e apresentaram menores necessidades de tratamento quando confrontados com os residentes em áreas periféricas menos privilegiadas.

LOYOLA et al. (2002) comentam que existe pouca informação passível de documentar adequadamente as iniqüidades em saúde na região das Américas. Destacam que "entre as dificuldades que os gestores de saúde têm enfrentado, está a pouca disponibilidade de dados específicos desagregados, a carência de ferramentas analíticas mais eficientes que considerem a dimensão geográfica, e a ausência de guias e exemplos baseados em informações gerais".

Em representação espacial das taxas brutas de incidência por neoplasia maligna da boca entre 100.000 homens para o ano de 2002 , o INCA (2002) relatou que esta se encontra entre 9,2 e 20,1 nos Estados de São Paulo, Rio de Janeiro, Espírito Santo e Região Sul do país, observandose taxas inferiores nas outras regiões. Para as mulheres, o documento relata uma taxa entre 2,83 e 6,89 por 100.000 para a Região Sudeste e Paraná. 


\section{OBJETIVOS}

\subsection{Objetivo Geral}

Estudar a série temporal dos coeficientes de mortalidade por câncer bucal e glândulas salivares no Município de São Paulo no período de 1980 a 2000.

\subsection{Objetivos Específicos}

3.2.1. Descrever a mortalidade por câncer bucal e glândulas salivares no Município de São Paulo, segundo sexo e localização anatômica da lesão, de 1980 a 2000.

3.2.2. Analisar a tendência dos coeficientes de mortalidade por câncer bucal e glândulas salivares para o Município, no período de 1980 a 2000.

3.2.3. Analisar a distribuição espacial dos óbitos por câncer bucal e glândulas salivares, associando-os com os índices de desenvolvimento social dos distritos do Município de São Paulo, no período de 1994 a 2000. 


\section{MÉTODOS}

Trata-se de um estudo descritivo. O método epidemiológico utilizado para a realização do levantamento da mortalidade por câncer bucal e glândulas salivares no Município de São Paulo entre 1980 e 2000 foi o de série temporal ou estudo de tendências, de base territorial. ALMEIDA FILHO e ROUQUAYROL (2002) comentam que vários autores classificam este tipo de estudo como um subtipo dos estudos ecológicos.

As variáveis dependentes (mortalidade por câncer bucal segundo a localização anatômica) foram calculadas com base em dados coletados junto à Fundação Sistema Estadual de Análise de Dados (SEADE), de 1980 a 2000, segundo a Classificação Internacional das Doenças, $9^{\text {a }}$ edição (CID9) sob os códigos 140.0 a 145.9, e CID-10, códigos C00.0 a C08.9. A $9^{\mathrm{a}}$ edição da CID foi utilizada até 1995; em 1996, o registro de óbitos passou a adotar a $10^{\mathrm{a}}$ revisão.

Os coeficientes de mortalidade foram calculados para cada ano, segundo a localização anatômica e foram padronizados por idade. A estimação das tendências de mortalidade por câncer bucal, segundo localização anatômica, e glândulas salivares seguiu indicação metodológica utilizada por Antunes e Waldman (2002). 
Para a apresentação gráfica das séries temporais segundo localização anatômica, foi utilizado o método de alisamento de séries temporais por médias móveis de ordem 5 (Gaynor e Kilkpatrick, 1994).

Quadro 4.1. Equivalências dos códigos da $9^{\mathrm{a}}$ e $10^{\mathrm{a}}$ revisões da Classificação Internacional das Doenças.

\begin{tabular}{|l|c|c|}
\hline LOCALIZAÇĀO ANATÓMICA & CID-9 & CID-10 \\
\hline assoalho bucal & 144.0 a 144.9 & C04.0 a C04.9 \\
gengiva & 143.0 a 143.9 & C03.0 a C03.9 \\
glândulas salivares & 142.0 a 142.9 & C07 a C08.9 \\
lábio & 140.0 a 140.9 & C00.0 a C00.9 \\
língua & 141.0 a 141.9 & C01 a C02.9 \\
mucosa oral & 145.0 & C06.0 \\
partes não especificadas & 145.8 e 145.9 & C06.9 \\
palato & 145.2 a 145.5 & C05.0 a C05.9 \\
retromolar & 145.6 & C06.2 \\
Vestíbulo da boca & 145.1 & C06.1 \\
\hline
\end{tabular}

Os dados populacionais para o cômputo de coeficientes foram coletados dos censos de 1980, 1991, e 2000, além da contagem populacional de 1996, por meio do Instituto Brasileiro de Geografia e Estatística (IBGE). Os indicadores de condição socioeconômica dos distritos do município foram calculados com base em informação do censo de $2000 \mathrm{e}$ têm como base os recenseamentos gerais de população: renda familiar, coeficiente de Gini, aglomeração domiciliar, condições de moradia, níveis de desemprego, coeficiente de analfabetismo e indicadores de nível educacional.

Levantou-se, para cada um dos 96 distritos do Município de São Paulo, as rendas média, mediana e per capita, com base no número de 
salários-mínimo (SM), conforme publicados pelo censo de 2000 (IBGE, 2002). As rendas média e mediana referem-se aos vencimentos familiares, e a renda per capita, à razão da renda média com o número de pessoas de uma mesma família que vivem com a renda supra-citada.

Outra variável que contribui para a observação da condição socioeconômica da população, o domicílio quitado, refere-se à proporção da população que vive em domicílio próprio.

A variável aglomeração domiciliar corresponde à razão do número de moradores de um domicílio pelo número de cômodos do mesmo. Quanto maior o índice de aglomeração domiciliar, piores as condições de moradia dessa população.

O grau de instrução, e também o número de anos de estudo foram outras variáveis mensuradas. Os grupos foram selecionados, segundo tais variáveis em: chefe da família sem instrução ou com primeiro grau incompleto, chefe da família com segundo grau completo e chefe da família com formação universitária. Além disso, como mensuração complementar, associou-se o número de anos de estudo à variável dependente óbito por câncer bucal.

O coeficiente de Gini é baseado na curva de Lorenz, uma curva de freqüência acumulada que compara a distribuição de uma variável especifica com a distribuição uniforme que representaria a igualdade (CASTILLOSALGADO et al., 2001). Trata-se de um indicador de desigualdade na distribuição de renda, pode variar de 0 (zero) a 1 (um). Zero equivaleria à 
distribuição homogênea numa sociedade na qual todos teriam exatamente a mesma parcela de renda; 1 , por sua vez, equivaleria à situação teórica na qual toda a renda fosse apropriada por um único indivíduo. Em 1995, de 100 países para os quais existiam dados comparáveis, o coeficiente de Gini variou de 0,26 a 0,60 (CONSTANCE, 1998). Na América Latina e no Caribe, de 0,59 no Brasil a 0,43 no Uruguai (CONSTANCE, 1998).

O estudo previu dois níveis de agregação para observação dos dados de mortalidade. No primeiro, a unidade é o Municipio de São Paulo como um todo, e a observação foi ordenada temporalmente de modo dirigido aos diferenciais por localização anatômica das neoplasias e sexo. No segundo nível de agregação dos dados de mortalidade, a unidade correspondeu a cada um dos 96 distritos do Municipio. Nesse sentido, para que a estimação de coeficientes de mortalidade fosse minimamente contemplada pelo volume de eventos em cada distrito, os dados de mortalidade foram agregados para 7 anos no periodo mais recente (1994-2000).

Realizou-se análise por conglomerados com base na variável dependente - coeficiente de mortalidade por câncer bucal e glândulas salivares. Segundo ROUQUAYROL e ALMEIDA FILHO (1999), um conglomerado de casos ou de óbitos corresponde a "um conjunto de casos ou de óbitos para os quais poder-se-ia hipotetizar origem idêntica, seja a ação de uma substância química, de um agente infeccioso, a retirada de um fator ambiental e, até mesmo, os modos de vida"; os autores explicam ainda que conglomerado espacial de casos se refere a "casos de doença de etiologia conhecida ou desconhecida, com doentes exibindo sintomas e 
sinais iguais, para os quais pode ser suspeitada ou evidenciada uma origem idêntica, ou mesmo comum, associada a algum fator ou fatores surgidos em território circunscrito cujos limites possam ser perfeitamente definidos". O uso da análise de conglomerados não pré-estabeleceu pontos arbitrários de corte. Com base nos valores relacionados ao coeficiente de mortalidade por câncer bucal estabelecidos para cada distrito, procedeu-se às estimativas de classificação desses distritos em conglomerados. Para a classificação das taxas de mortalidade em conglomerados, utilizou-se a metodologia de "kmeans cluster analysis", conforme descrita por JOHNSON e WICHERN (1998).

Os dados assim produzidos foram apresentados sob a forma de gráficos e tabelas. Os coeficientes de mortalidade foram padronizados por sexo e faixa etária, permitindo que o reconhecido efeito dessas variáveis sobre a mortalidade por câncer bucal não interferisse na identificação de tendências e diferenciais na distribuição espacial dos coeficientes. Foi utilizada a análise de regressão linear simples para o cálculo de tendências.

O coeficiente de correlação 'r' de Pearson ou regressão linear simples (OLS) foi utilizado para verificar o relacionamento entre o coeficiente de mortalidade por câncer bucal e os indicadores de desenvolvimento socioeconômico dos distritos. Segundo LEVIN (1978), o coeficiente de correlação de Pearson oferece uma medida da "força (grifo do original) e do sentido (grifo do original) da correlação existente entre as variáveis". (LEVIN, 1978, p. 216). 
Para a obtenção da razão entre os conglomerados com piores coeficientes de mortalidade por câncer bucal e glândulas salivares e os que possuiam melhores taxas, foram considerados 2 agregados. Um, agregando os distritos com maiores coeficientes de mortalidade por câncer bucal no período de 1994 a 2000 (Conglomerados 4 e 5), e outra que associou os distritos onde se observou menor coeficiente de mortalidade nesse mesmo período (Conglomerados 1, 2 e 3). Assim, com base na nova definição de área, foram recalculados os novos coeficientes de mortalidade, segundo a localização anatômica, e procedeu-se a sua comparação nesse período.

Os coeficientes obtidos para as 2 novas áreas foram padronizados segundo sexo e idade; assim, procedeu-se à obtenção do coeficiente entre as 2 medidas para estimar, de modo quantitativo, o excesso de óbitos nas áreas de maior mortalidade em relação às áreas com menor mortalidade. Em seguida, o mesmo procedimento foi adotado para cada localização anatômica, com sua distribuição mais discrepante e menos discrepante na geografia urbana.

A presente pesquisa envolveu apenas o estudo documental de dados secundários e de literatura, tendo sido aprovada pelo Comitê de Ética em Pesquisa (CEP) da Faculdade de Saúde Pública da Universidade de São Paulo, protocolo $n^{\circ} 689$. Nesse sentido, pode-se dizer que o estudo não envolveu contato direto com seres humanos. O acervo dos dados de mortalidade é consolidado anualmente pela Fundação SEADE que os disponibiliza para consulta pública. Também os dados de população fornecidos pelos censos são de domínio público. Os bancos de dados de 
mortalidade não permitem a identificação individual das pessoas que faleceram a cada ano, registrando apenas as suas características de interesse para a presente pesquisa. 


\section{RESULTADOS}

No período de 1980 a 2000, houve 3.942 óbitos por câncer bucal e glândulas salivares no Municipio de São Paulo, com uma tendência global de estabilidade.

Tabela 5.1. Freqüências absoluta e relativa e tendência dos óbitos por câncer bucal e glândulas salivares segundo a localização anatômica da lesão, Município de São Paulo, 1980-2000.

\begin{tabular}{lcccccc}
\hline $\begin{array}{l}\text { Localização } \\
\text { anatômica }\end{array}$ & $\begin{array}{c}\text { No. } \\
\text { casos }\end{array}$ & $\%$ & Tendência & \multicolumn{2}{c}{ IC (95\%) } & Interpretação \\
\hline assoalho & 328 & 8,41 & $-1,42$ & $-4,96$ & 2,25 & estável \\
gengiva & 96 & 2,46 & $-7,69$ & $-13,21$ & $-1,81$ & declínio \\
gl. salivares & 348 & 8,92 & 0,38 & $-1,68$ & 2,49 & estável \\
lábio & 78 & 2,00 & $-8,73$ & $-11,67$ & $-5,69$ & declínio \\
língua & 1945 & 49,85 & 0,31 & $-0,59$ & 1,22 & estável \\
mucosa oral & 24 & 0,61 & & & & não se aplica * \\
não espec. & 660 & 16,91 & 4,70 & 2,89 & 6,55 & crescente \\
palato & 318 & 8,15 & 0,15 & $-2,34$ & 2,72 & estável \\
retromolar & 101 & 2,59 & $-0,23$ & $-3,14$ & 2,77 & estável \\
vestíbulo & 4 & 0,10 & \multicolumn{5}{c}{0} & não se aplica* \\
\hline total & 3902 & 100 & 0,32 & $-0,81$ & 1,46 & estável \\
\hline *O número de óbitos associados a vestíbulo da boca e mucosa oral foi muito pequeno para \\
permitir a aplicação do método de estimação de tendência. & &
\end{tabular}

O câncer de língua foi responsável, no período, pela maioria dos óbitos ocorridos, com 1945 casos de óbitos (49,9\%) (Tabela 5.1). Ao câncer de língua, seguiram-se partes não especificadas da cavidade bucal, com 660 
óbitos (16,9\% do total); as localizações anatômicas que apresentaram menor proporção de óbitos foram mucosa oral e vestíbulo da boca com, respectivamente, $24(0,6 \%)$ e $4(0,01 \%)$ óbitos entre 1980 e 2000 (Tabela $5.1)$.

Apesar de ter sido encontrada tendência global de estabilidade, os óbitos por câncer bucal selecionados por localização anatômica apresentaram diversas tendências (Tabela 5.1): de declínio para gengiva e lábio, com tendência de $7,69 \%$ de redução anual de óbitos (95\% IC -1,81 a 13,21) e $8,73 \%$ (95\% IC $-5,69$ a $-11,67)$, respectivamente; estável para assoalho de boca, glândulas salivares, língua, palato e área retromolar, e de aumento para partes não especificadas da cavidade oral, com valor de $4,70 \%(95 \%$ IC 2,89 a 6,55$)$.

Não foi possível a estimação de tendências para os óbitos da mucosa oral e vestíbulo da boca, em função do baixo número de óbitos ocorridos no período. 


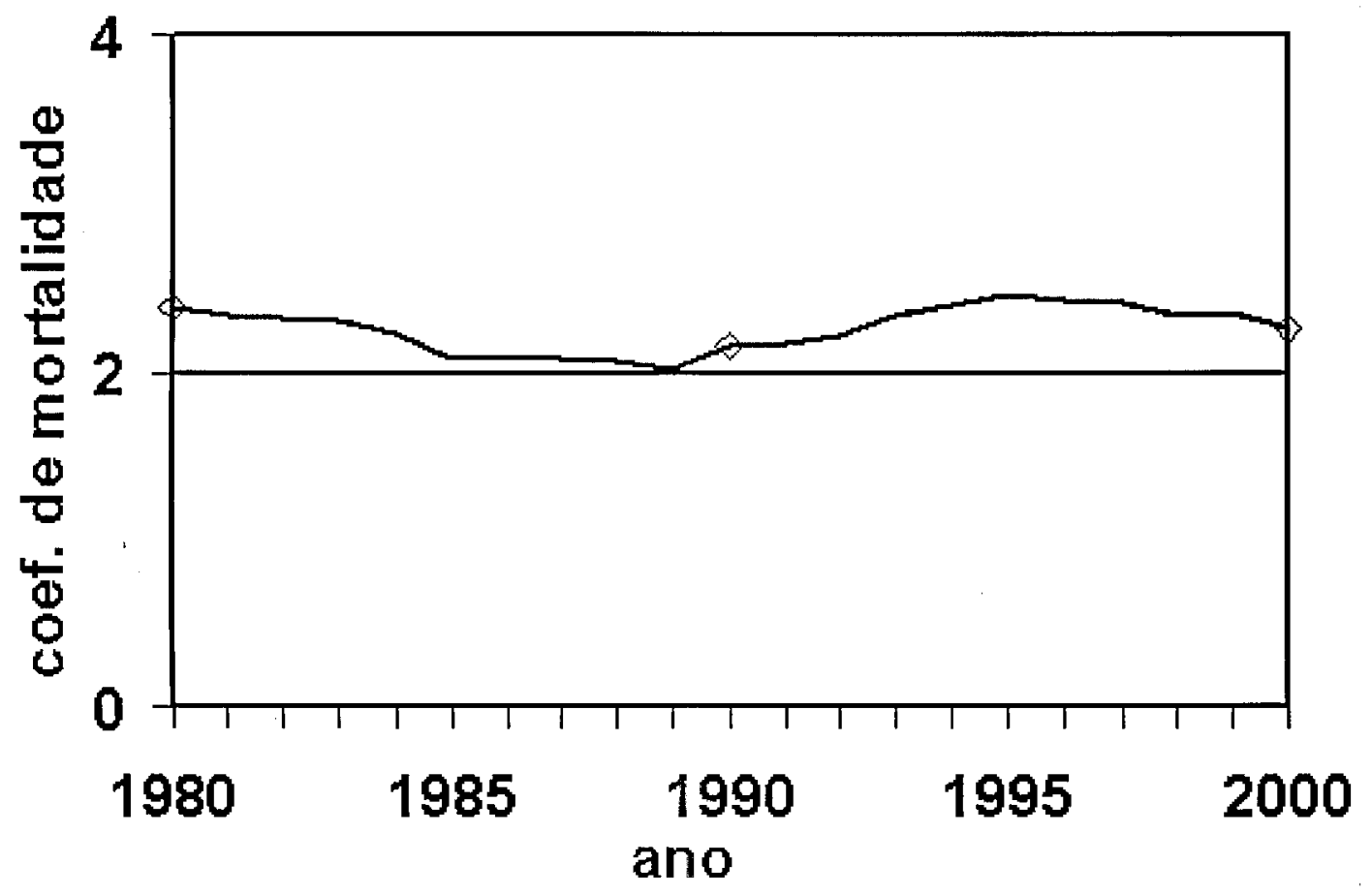

Figura 5.1. Coeficiente padronizado (por gênero e grupo etário) e alisado (MM5) $^{1}$ de mortalidade por câncer bucal e glândulas salivares (códigos C00.0 - C08.9 da CID-10) por 100.000 habitantes para o Município de São Paulo, 1980-2000.

A Figura 5.1 mostra o coeficiente padronizado por gênero e grupo etário e alisado pelo método de médias móveis de ordem 3 de mortalidade por câncer bucal e glândulas salivares no período de 1980 a 2000; sua inspeção visual confirma o achado na Tabela 5.1, onde foi verificada uma tendência global estável de mortalidade no período estudado. 


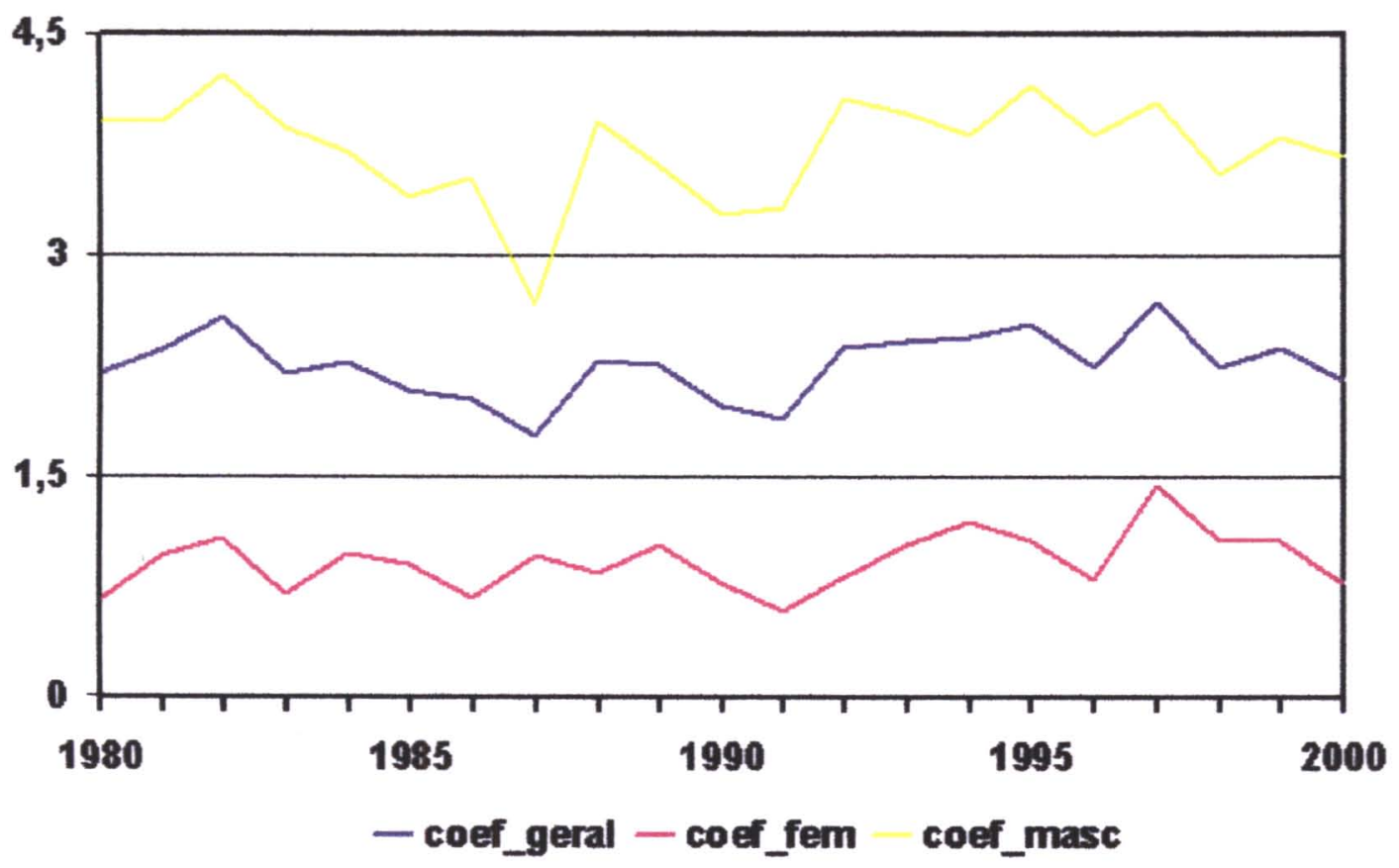

Figura 5.2. Coeficiente padronizado (por grupo etário) masculino e feminino de mortalidade por câncer bucal e glândulas salivares por 100.000 habitantes segundo o sexo e ambos, para o Município de São Paulo, 19802000.

A análise da Figura 5.2 permite observar que o coeficiente padronizado por grupo etário de mortalidade por câncer bucal e glândulas salivares entre as mulheres foi de um terço, aproximadamente do coeficiente para os homens, no período estudado. 


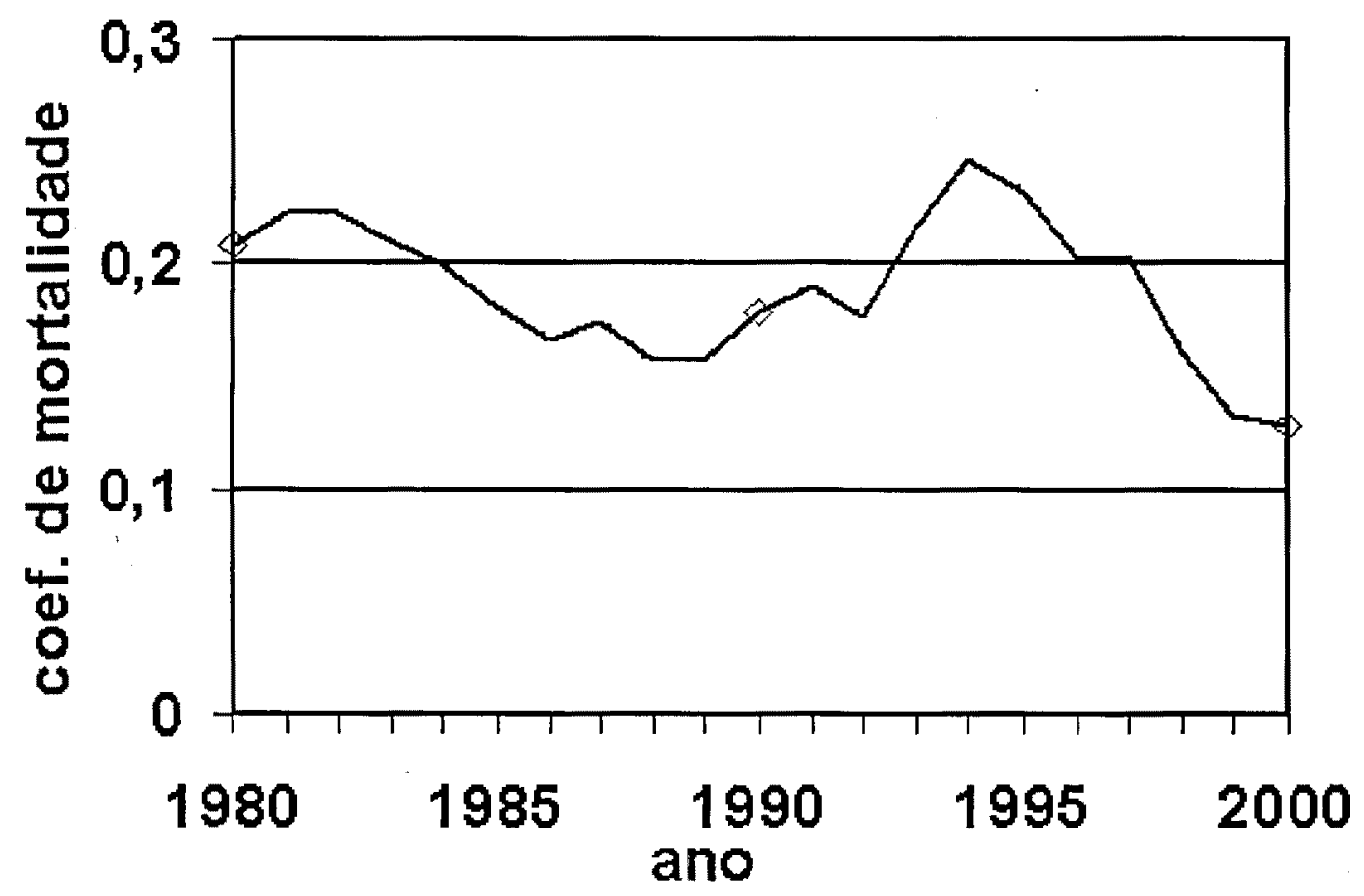

Figura 5.3. Coeficiente padronizado (por gênero e grupo etário) e alisado (MM5) de mortalidade por neoplasia no assoalho de boca (códigos C04.0 C04.9 da CID-10) por 100.000 habitantes para o Município de São Paulo, 1980-2000.

A Figura 5.3 mostra série histórica da mortalidade por câncer de assoalho bucal no período de 1980 a 2000 . Observa-se que o coeficiente de mortalidade oscilou em torno de 0,2 por 100.000 habitantes. 


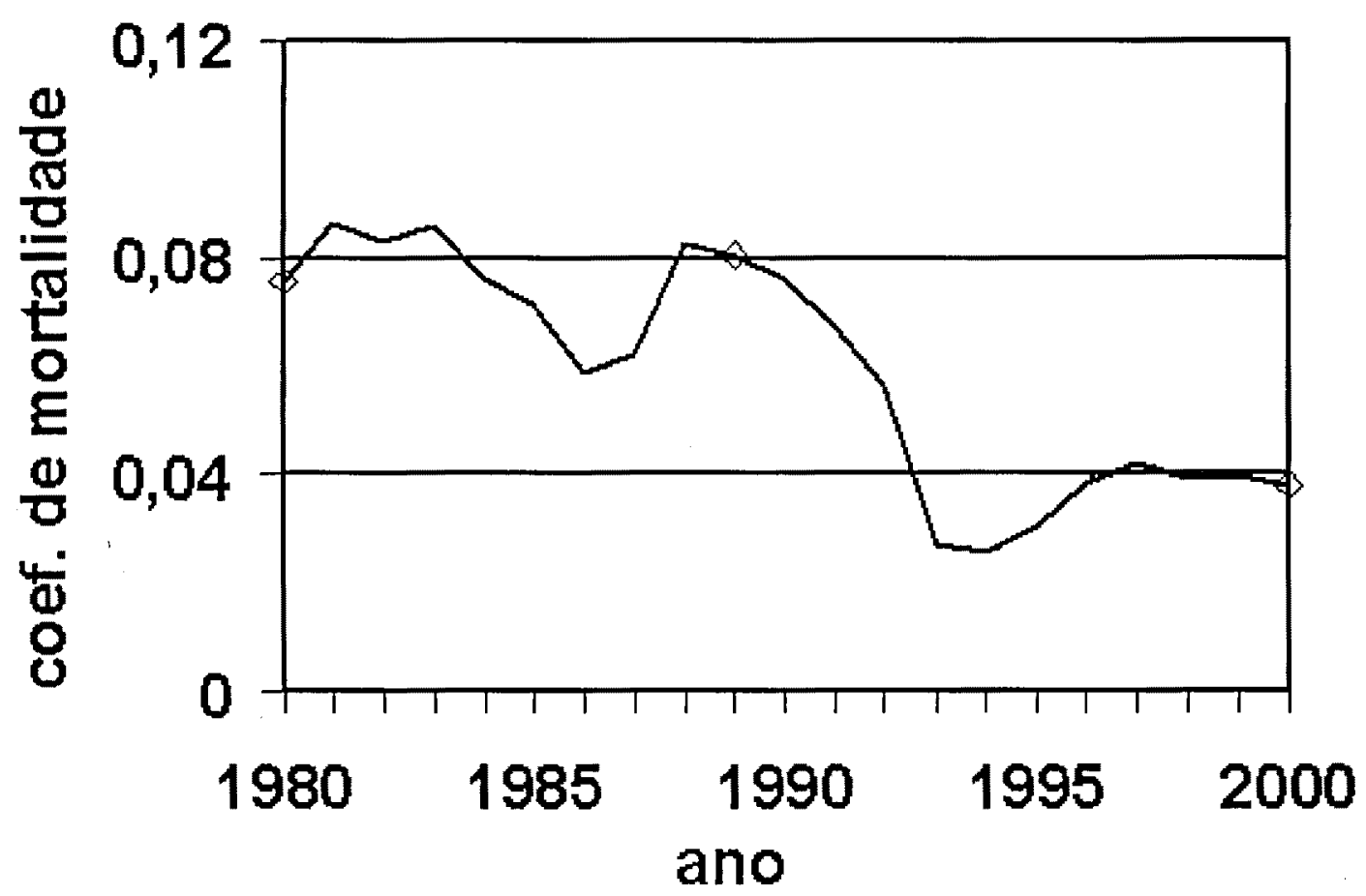

Figura 5.4. Coeficiente padronizado (por gênero e grupo etário) ) e alisado (MM5) de mortalidade por neoplasia na gengiva (códigos C03.0 - C03.9 da CID-10) por 100.000 habitantes para o Município de São Paulo, 1980-2000.

A Figura 5.4 mostra série histórica da mortalidade por câncer de gengiva no período de 1980 a 2000. Observa-se que o coeficiente de mortalidade oscilou entre 0,04 e 0,08 por 100.000 habitantes. 


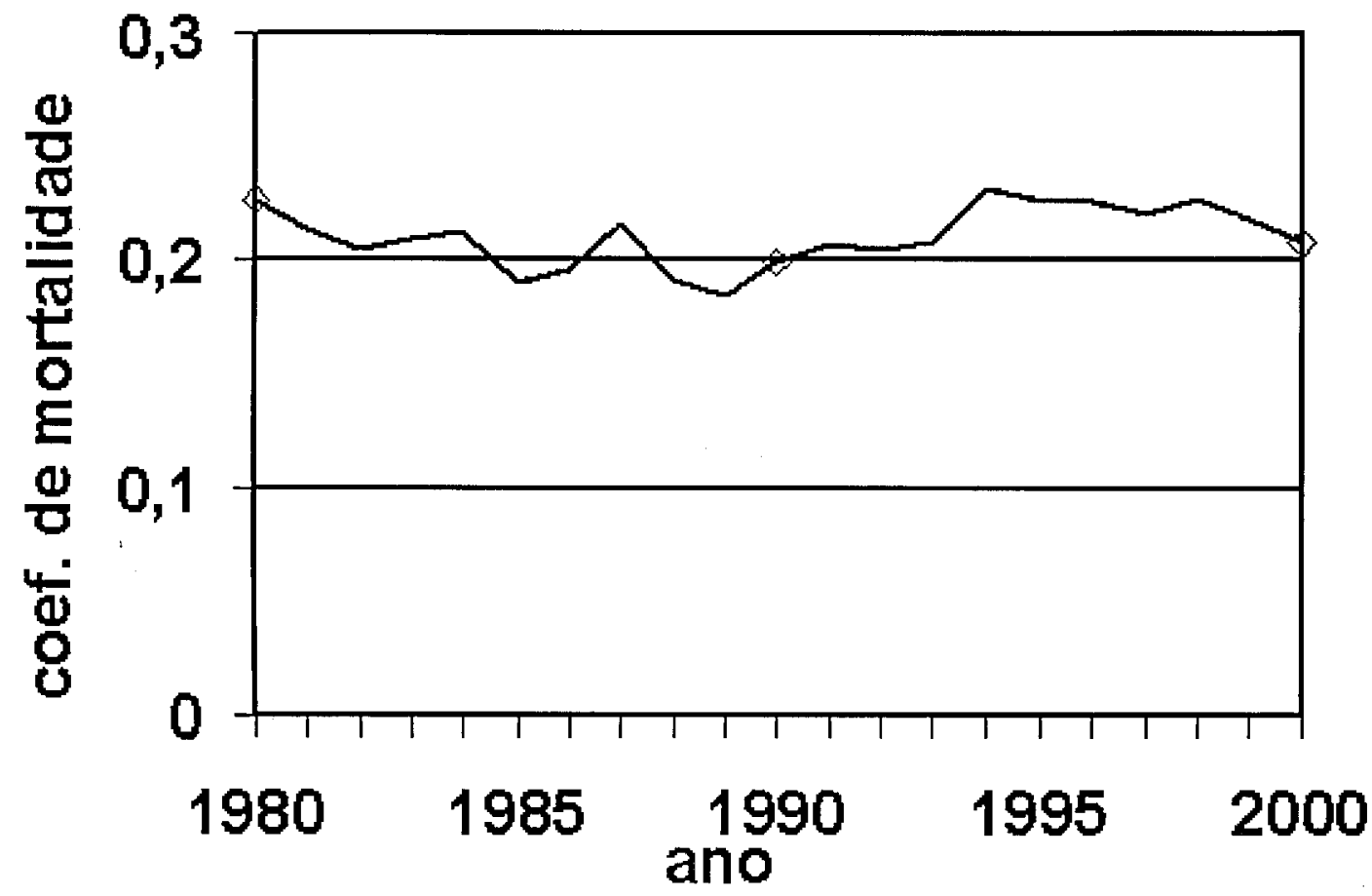

Figura 5.5. Coeficiente padronizado (por gênero e grupo etário)) e alisado (MM5) de mortalidade por neoplasia em glândulas salivares (códigos C07 C08.9 da CID-10) por 100.000 habitantes para o Município de São Paulo, 1980-2000.

A Figura 5.5 mostra série histórica da mortalidade por câncer de glândulas salivares no período de 1980 a 2000. Observa-se que o coeficiente de mortalidade oscilou em torno de 0,2 por 100.000 habitantes. 


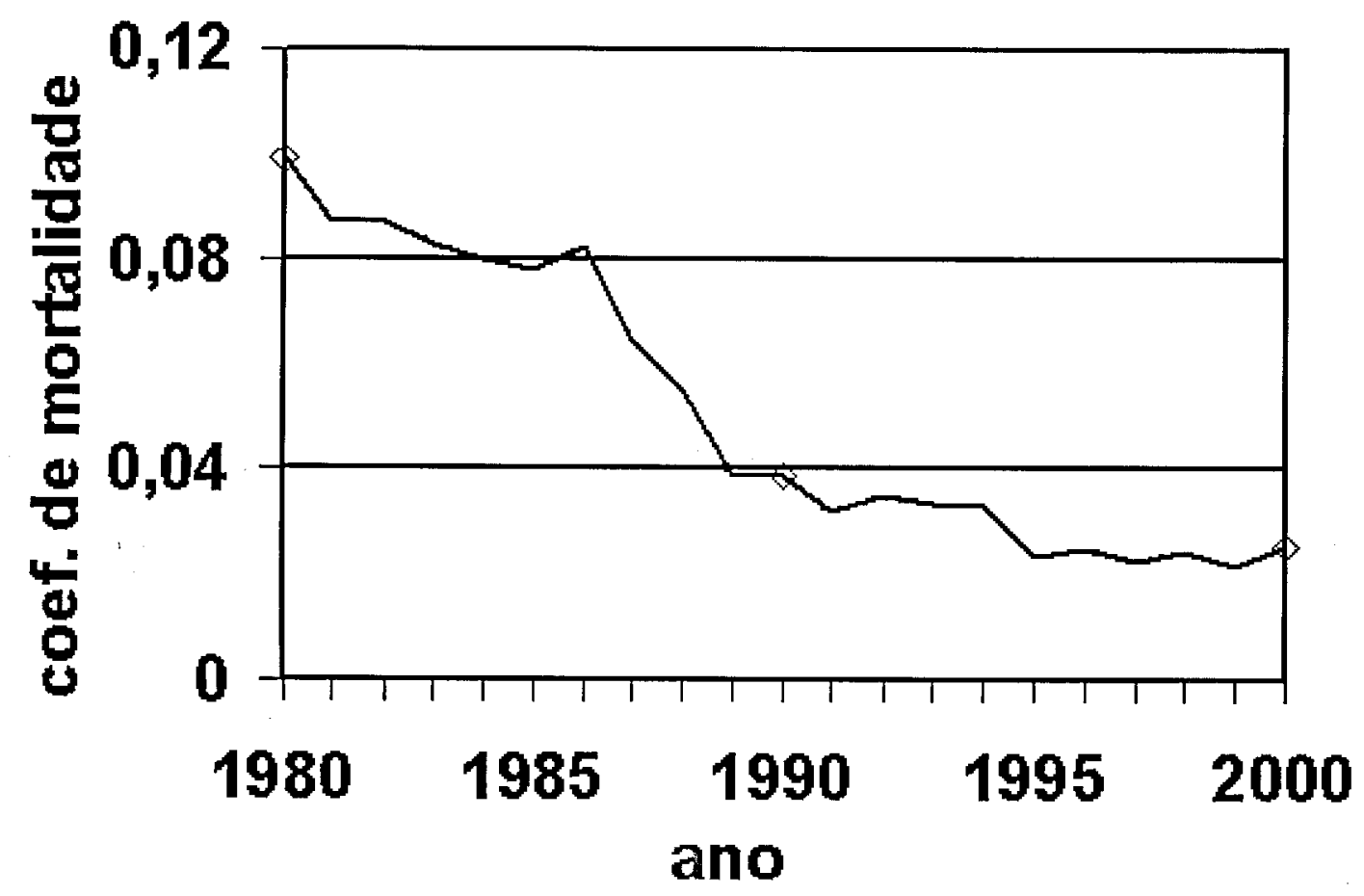

Figura 5.6. Coeficiente padronizado (por gênero e grupo etário) ) e alisado (MM5) de mortalidade por neoplasia em lábio (códigos C00.0 - C00.9 da CID-10) por 100.000 habitantes para o Município de São Paulo, 1980-2000.

A Figura 5.6 mostra série histórica da mortalidade por câncer de lábio no período de 1980 a 2000 . A inspeção visual do gráfico permite observar o que já fora confirmado na Tabela 5.1: tendência de declínio de óbitos por esta localização anatômica. Observa-se que o coeficiente de mortalidade iniciou com aproximadamente 0,10 e depois declinou, atingindo patamares próximos a 0,02 por 100.000 habitantes. 


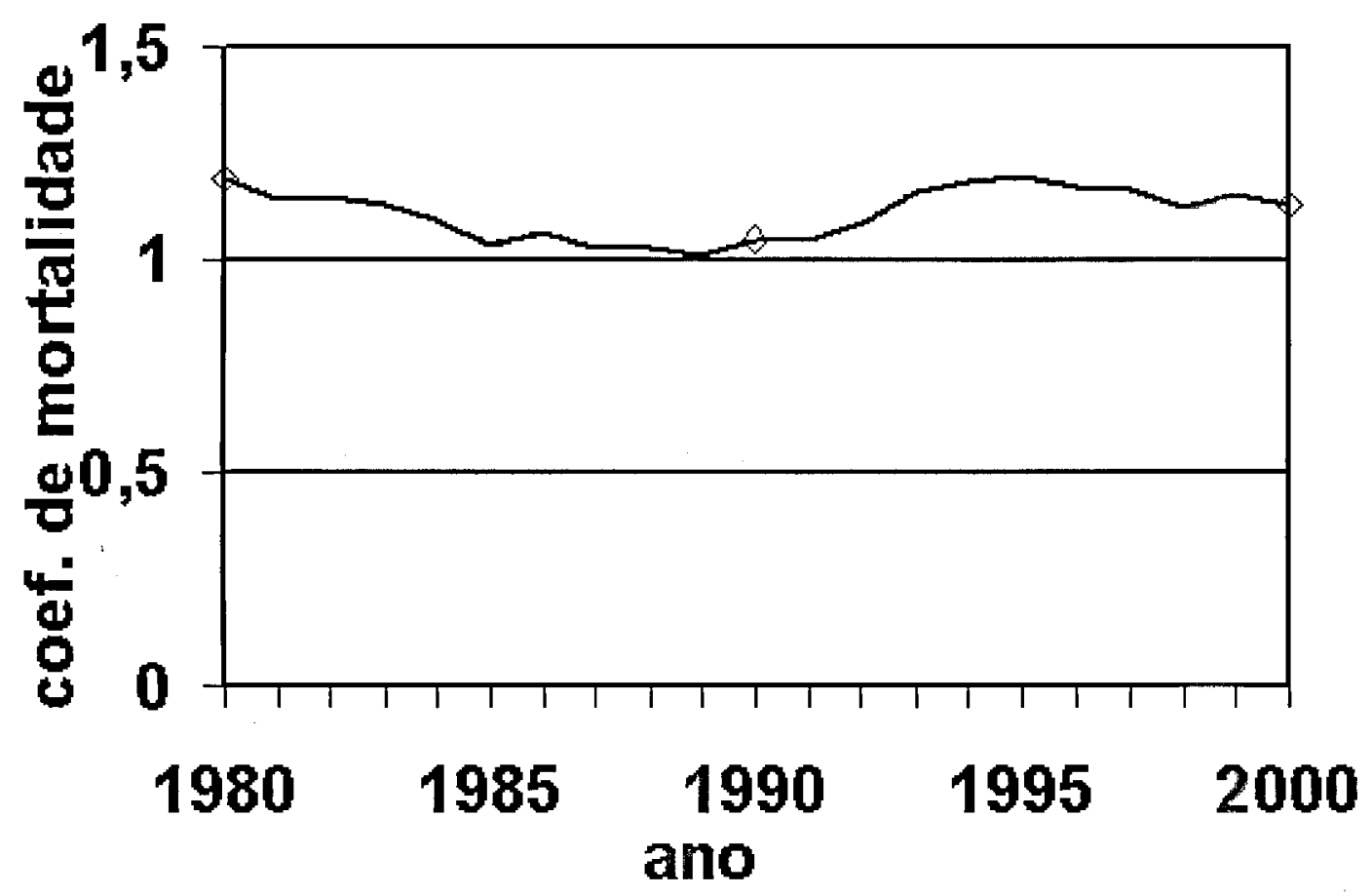

Figura 5.7. Coeficiente padronizado (por gênero e grupo etário) ) e alisado (MM5) de mortalidade por neoplasia na língua (códigos C01 - C02.9 da CID10) por 100.000 habitantes para o Município de São Paulo, 1980-2000.

A Figura 5.7 mostra série histórica da mortalidade por câncer de língua no período de 1980 a 2000. Observa-se que o coeficiente de mortalidade oscilou em torno de 1,2 por 100.000 habitantes, com tendência estável. 


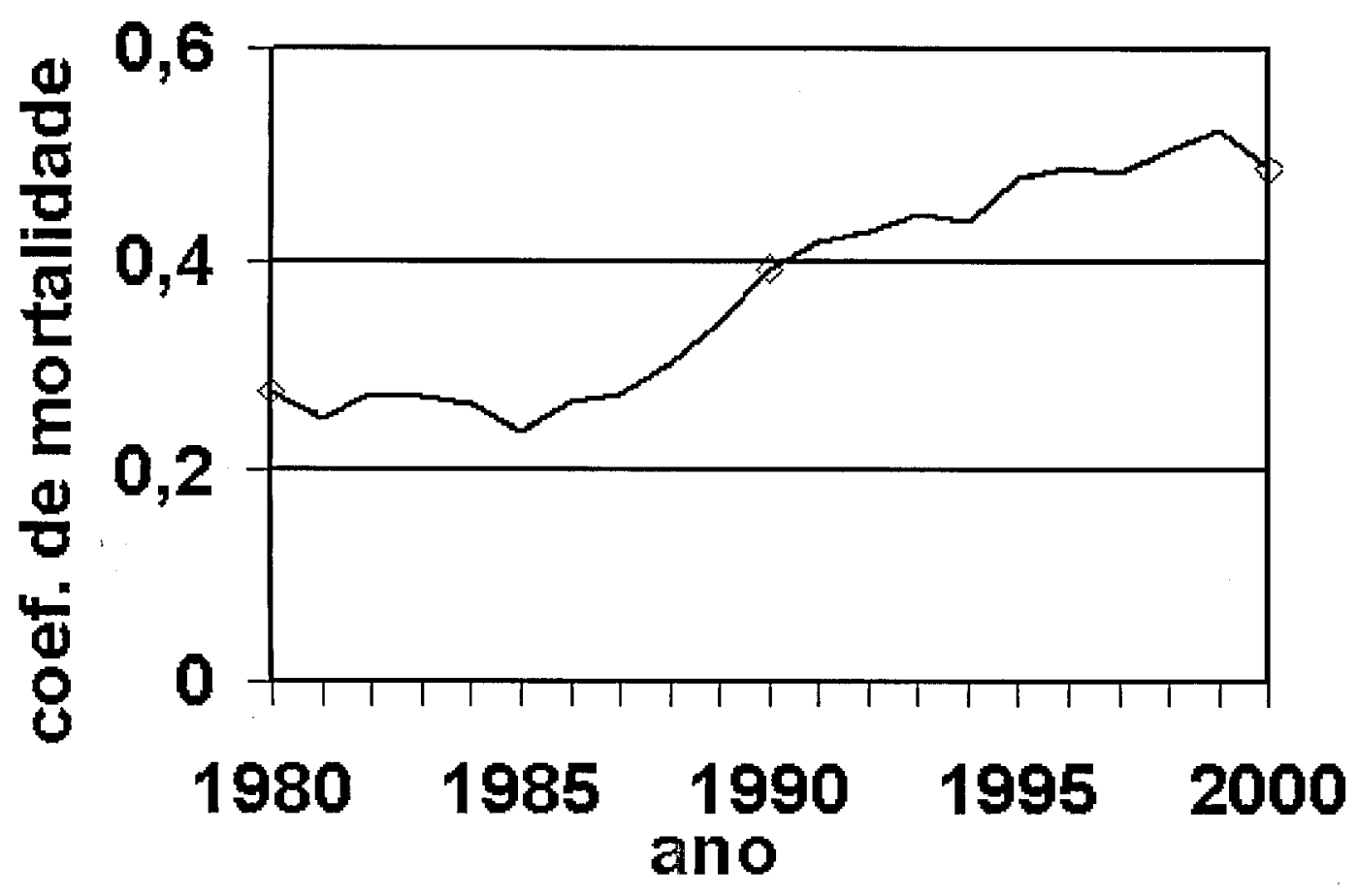

Figura 5.8. Coeficiente padronizado (por gênero e grupo etário) ) e alisado (MM5) de mortalidade por neoplasia em partes não especificadas da boca (código C06.9 da CID-10) por 100.000 habitantes para o Município de São Paulo, 1980-2000.

A Figura 5.8 mostra série histórica da mortalidade por câncer de partes não especificadas da cavidade bucal no período de 1980 a 2000. Esta localização anatômica foi a única que apresentou tendência de aumento (Tabela 5.1) no período estudado. Observa-se que, em 1980, o coeficiente padronizado de mortalidade foi de aproximadamente 0,3 , passando para em torno de 0,5 por 100.000 habitantes em 2000 . 


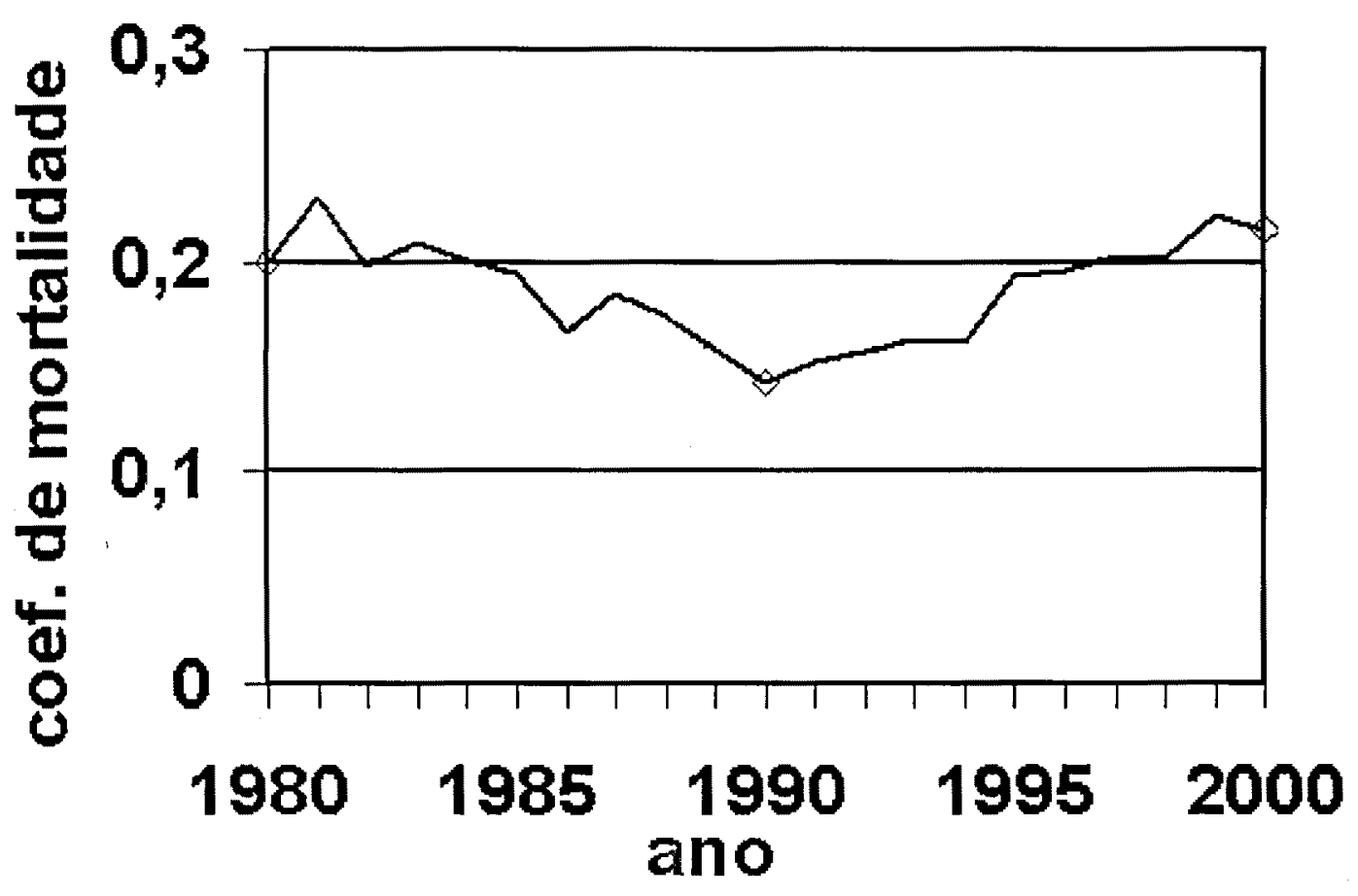

Figura 5.9. Coeficiente padronizado (por gênero e grupo etário)) e alisado (MM5) de mortalidade por neoplasia no palato (códigos C05.0 - C05.9 da CID-10) por 100.000 habitantes para o Municipio de São Paulo, 1980-2000.

A Figura 5.9 mostra série histórica da mortalidade por câncer de palato no periodo de 1980 a 2000. Observa-se que o coeficiente de mortalidade oscilou em torno de 0,2 por 100.000 habitantes. 


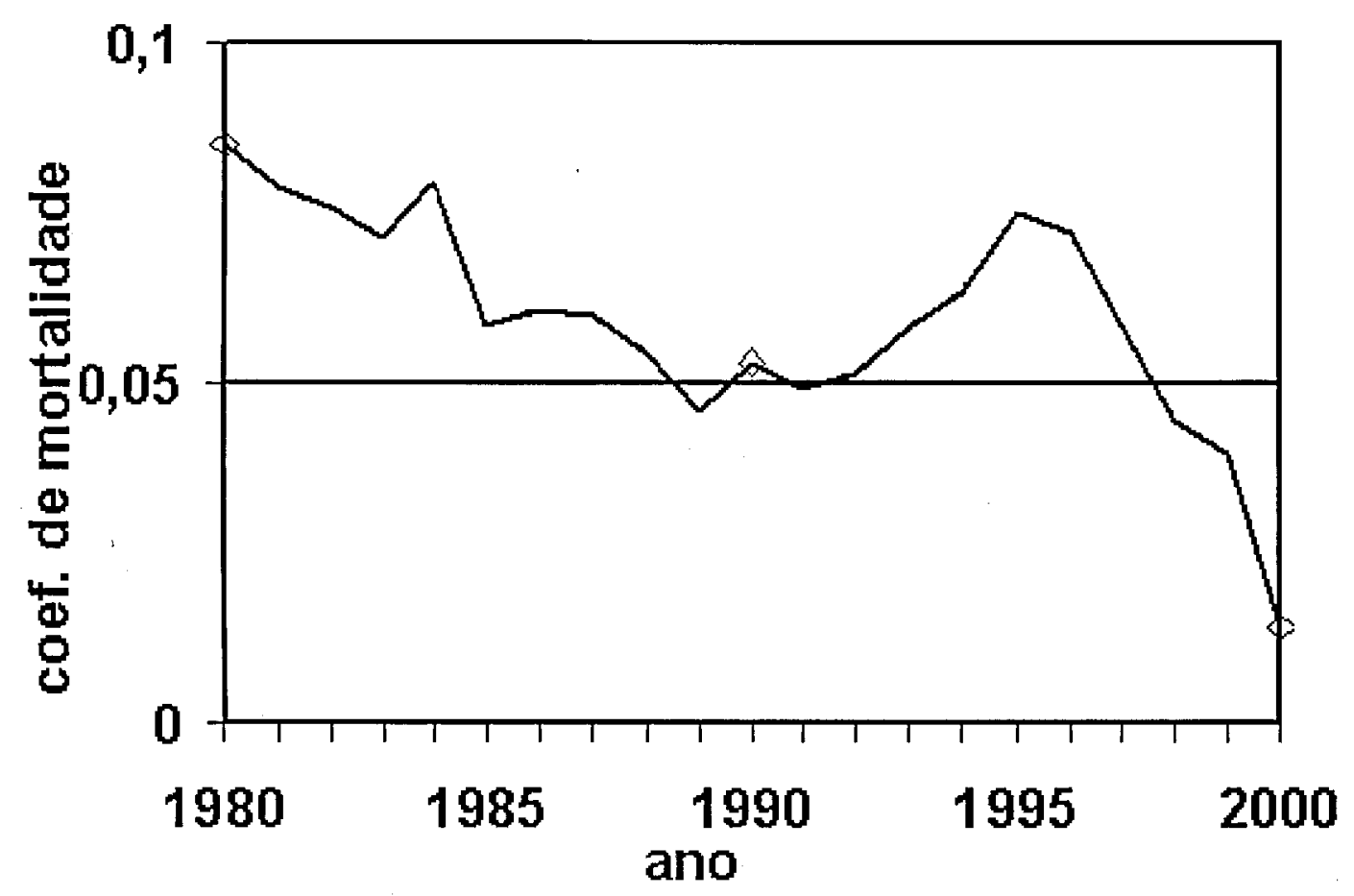

Figura 5.10. Coeficiente padronizado (por gênero e grupo etário)) e alisado (MM5) de mortalidade por neoplasia na região retromolar (código C06.2 da CID-10) por 100.000 habitantes para o Município de São Paulo, 1980-2000.

A Figura 5.10 mostra série histórica da mortalidade por câncer da região retromolar no período de 1980 a 2000 . Observa-se que o coeficiente de mortalidade oscilou em torno de 0,05 por 100.000 habitantes.

No período de 1994 a 2000, observou-se um total de 1486 óbitos por câncer bucal e glândulas salivares no Município de São Paulo; desses, 41 apresentaram-se, no banco de dados estudados, sem especificação do distrito de residência do paciente que veio a óbito. Assim, o presente estudo contou com 1445 óbitos para a análise espacial da mortalidade.

Nos 96 distritos, foi encontrado que 8 deles apresentaram menos de 5 óbitos no período, 20 distritos apresentaram entre 5 e 9 óbitos, 42 deles apresentaram entre 10 e 19, e, finalmente, 26 distritos apresentaram entre 
20 e 43 óbitos por câncer bucal.

Os Quadros 5.1 a 5.5 mostram os distritos do Município de São Paulo, segundo o coeficiente de mortalidade padronizado por sexo e faixa etária por câncer bucal e glândulas salivares. A população dos distritos pertencentes ao conglomerado 1 experimentaram risco menor que a população dos outros conglomerados de vir a óbito por essa patologia. A população residente no conglomerado 5, por sua vez, foi a que apresentou o maior risco. 0 coeficiente de mortalidade por câncer bucal e glândulas salivares no período entre 1994 e 2000 foi de 16,71 para o Municipio de São Paulo, que possui população de 10.434.252 habitantes (IBGE, 2002).

Quadro 5.1. Distritos correspondentes ao conglomerado com menor risco de óbito por câncer bucal e glândulas salivares, população de cada distrito, e coeficiente de mortalidade padronizado por sexo e faixa etária por 100.000 habitantes para o Municipio de São Paulo, período de 1994 a 2000.

\begin{tabular}{|l|c|c|}
\hline CONGLOMERADO 1 & População & Coef. de mort./100.000 \\
\hline Alto de Pinheiros & 44.454 & 7,31 \\
Butantã & 52.649 & 7,84 \\
Campo Limpo & 191.527 & 8,92 \\
Iguatemi & 101.780 & 9,20 \\
Itaim Bibi & 81.456 & 8,34 \\
Jardim Paulista & 83.667 & 6,71 \\
Liberdade & 61.875 & 7,59 \\
Moema & 71.276 & 8,34 \\
Rio Pequeno & 111.756 & 7,37 \\
Socorro & 39.097 & 5,68 \\
Vila Andrade & 73.649 & 6,99 \\
Vila Leopoldina & 26.870 & 4,19 \\
\hline Total & 940.056 & 6,90 \\
\hline
\end{tabular}


Quadro 5.2. Distritos correspondentes ao conglomerado com o segundo menor risco de óbito por câncer bucal e glândulas salivares, população de cada distrito, e coeficiente de mortalidade padronizado por sexo e faixa etária por 100.000 habitantes para o Município de São Paulo, período de 1994 a 2000.

\begin{tabular}{|l|c|c|}
\hline CONGLOMERADO 2 & População & Coef. de mort./100.000 \\
\hline Bela Vista & 63.190 & 11,34 \\
Brasilândia & 247.328 & 12,38 \\
Campo Belo & 66.646 & 12,25 \\
Consolação & 54.522 & 13,29 \\
Itaim Paulista & 212.733 & 12,49 \\
Jaguara & 25.713 & 10,43 \\
Jardim Helena & 139.106 & 10,14 \\
Lajeado & 157.773 & 12,47 \\
Marsilac & 8.404 & 11,76 \\
Morumbi & 34.588 & 12,97 \\
Parelheiros & 102.836 & 13,32 \\
Pedreira & 127.425 & 12,65 \\
Perdizes & 102.445 & 12,53 \\
Pinheiros & 62.997 & 10,88 \\
República & 47.718 & 10,17 \\
Santa Cecilia & 71.179 & 10,09 \\
Santana & 124.654 & 11,97 \\
São Rafael & 125.088 & 12,04 \\
Sé & 20.115 & 9,94 \\
Tucuruvi & 99.368 & 13,21 \\
Vila Jacui & 141.959 & 11,11 \\
Vila Sônia & 87.379 & 11,61 \\
\hline Total & 2.123 .166 & 11,51 \\
\hline
\end{tabular}


Quadro 5.3. Distritos correspondentes ao conglomerado com o terceiro menor risco de óbito por câncer bucal e glândulas salivares, população de cada distrito, e coeficiente de mortalidade padronizado por sexo e faixa etária por 100.000 habitantes para o Município de São Paulo, período de 1994 a 2000.

\begin{tabular}{|l|c|c|}
\hline CONGLOMERADO 3 & População & Coef. de mort./100.000 \\
\hline Anhangüera & 38.427 & 15,13 \\
Aricanduva & 94.813 & 14,53 \\
Barra Funda & 12.965 & 14,09 \\
Campo Grande & 91.373 & 15,81 \\
Capão Redondo & 240.793 & 16,29 \\
Cidade Ademar & 243.372 & 16,24 \\
Cidade Tiradentes & 190.657 & 16,64 \\
Ermelino Matarazzo & 106.838 & 15,74 \\
Grajaú & 333.436 & 15,27 \\
Jabaquara & 214.095 & 15,15 \\
Jardim Ângela & 245.805 & 15,86 \\
Jardim São Luís & 239.161 & 14,71 \\
Parque do Carmo & 64.067 & 16,98 \\
Perus & 70.689 & 14,62 \\
Pirituba & 161.796 & 15,83 \\
Santo Amaro & 60.539 & 14,56 \\
São Domingos & 82.834 & 15,33 \\
Tatuapé & 79.381 & 17,29 \\
Vila Curuçá & 146.482 & 15,84 \\
Vila Maria & 113.845 & 14,34 \\
Vila Mariana & 123.683 & 15,63 \\
\hline Total & 2.955 .051 & 14,30 \\
\hline
\end{tabular}


Quadro 5.4. Distritos correspondentes ao conglomerado com o segundo maior risco de óbito por câncer bucal e glândulas salivares, população de cada distrito, e coeficiente de mortalidade padronizado por sexo e faixa etária por 100.000 habitantes para o Município de São Paulo, periodo de 1994 a 2000.

\begin{tabular}{|l|c|c|}
\hline CONGLOMERADO 4 & População & Coef. de mort./100.000 \\
\hline Artur Alvim & 111.210 & 20,22 \\
Bom Retiro & 26.598 & 20,91 \\
Cachoeirinha & 147.649 & 20,75 \\
Carrão & 78.175 & 18,69 \\
Casa Verde & 83.629 & 17,56 \\
Cidade Dutra & 191.389 & 19,26 \\
Freguesia do O & 144.923 & 17,49 \\
Itaquera & 201.512 & 17,64 \\
Jaçanã & 91.809 & 18,35 \\
José Bonifácio & 107.082 & 17,75 \\
Mandaqui & 103.113 & 20,57 \\
Mooca & 63.280 & 20,29 \\
Penha & 124.292 & 19,83 \\
Ponte Rasa & 98.113 & 20,21 \\
Raposo Tavares & 91.204 & 18,25 \\
Sacomã & 228.283 & 19,63 \\
São Lucas & 139.333 & 19,17 \\
São Mateus & 154.850 & 18,78 \\
São Miguel & 97.373 & 20,31 \\
Sapopemba & 282.239 & 19,48 \\
Saúde & 118.077 & 18,28 \\
Tremembé & 163.803 & 18,41 \\
Vila Matilde & 102.935 & 19,15 \\
Vila Medeiros & 140.564 & 18,82 \\
Vila Prudente & 102.104 & 19,40 \\
\hline Total & 3.193 .539 & 17,34 \\
\hline
\end{tabular}


Quadro 5.5. Distritos correspondentes ao conglomerado com o maior risco de óbito por câncer bucal e glândulas salivares, população de cada distrito, e coeficiente de mortalidade padronizado por sexo e faixa etária por 100.000 habitantes para o Município de São Paulo, período de 1994 a 2000.

\begin{tabular}{|l|c|c|}
\hline CONGLOMERADO 5 & População & Coef. de mort./100.000 \\
\hline Água Rasa & 85896 & 21,71 \\
Belém & 39622 & 29,81 \\
Brás & 25158 & 29,90 \\
Cambuci & 28717 & 22,50 \\
Cangaiba & 137442 & 24,80 \\
Cidade Lịder & 116841 & 21,80 \\
Cursino & 102089 & 21,64 \\
Guaianazes & 98546 & 22,79 \\
Ipiranga & 98863 & 22,22 \\
Jaguara & 25713 & 22,95 \\
Jaguaré & 42479 & 23,04 \\
Lapa & 60184 & 21,42 \\
Limão & 82045 & 21,94 \\
Pari & 14824 & 24,79 \\
Vila Formosa & 93850 & 24,23 \\
Vila Guilherme & 49984 & 24,98 \\
\hline Total & 1.102 .253 & 21,07 \\
\hline
\end{tabular}

Tabela 5.2. Informações sociodemográficas segundo conglomerados de áreas classificadas pelo risco de óbito por câncer bucal e glândulas salivares no Município de São Paulo, 2000.

Congl. 1 Congl. 2 Congl. 3 Congl. 4 Congl. 5

\begin{tabular}{lccccc}
\hline Anos estudo do chefe da família & 10,952 & 9,237 & 8,296 & 8,307 & 8,914 \\
Chefe sem instr. ou 1 $^{\circ}$ grau incompl. (\%) & 32,227 & 43,590 & 50,143 & 48,886 & 44,693 \\
Chefe com 2 $^{\circ}$ grau completo . (\%) & 55,485 & 41,444 & 33,172 & 33,716 & 38,787 \\
Chefe com formação universitária . (\%) & 32,875 & 20,360 & 13,182 & 10,855 & 14,378 \\
Renda média (em SM*) & 19,655 & 12,796 & 8,843 & 7,843 & 9,217 \\
Renda mediana (em SM*) & 11,948 & 8,129 & 5,547 & 4,911 & 5,502 \\
Renda média per capita (em SM*) . (\%) & 6,627 & 4,290 & 2,699 & 2,313 & 2,827 \\
Domicilio quitado . (\%) & 63,937 & 59,330 & 60,941 & 57,839 & 55,205 \\
Coeficiente de Gini & 0,460 & 0,473 & 0,498 & 0,502 & 0,505 \\
\hline Risco de óbito por câncer bucal & 0,441 & 0,705 & 0,928 & 1,147 & 1,423 \\
\hline
\end{tabular}

* Salários-mínimos (SM); valor de referência: R\$200,00, março de 2003.

Os chefes de família pertencentes ao conglomerado 1 apresentaram, em média, quase 11 anos de estudo, ao passo que os chefes de família 
pertencentes ao conglomerado 3 apresentaram pouco mais de 8 anos de estudo (Tabela 5.2).

A proporção de chefes de família sem instrução ou com $1^{\circ}$ grau incompleto foi maior para o conglomerado $3(50,1 \%)$ e menor para o conglomerado $1(32,2 \%)$ (Tabela 5.2).

Já a proporção de chefes de familia com formação universitária foi de $32,9 \%$ para os moradores do conglomerado 1 sendo o conglomerado 4 o que apresentou menor proporção destes com formação universitária (10,9\%) (Tabela 5.2).

A renda média foi de 19,7 salários mínimos (SM) para os moradores do conglomerado 1, e a renda per capita, 6,6 SM, o que indica uma situação média de aproximadamente 3 pessoas por núcleo familiar (Tabela 5.2). No conglomerado 5 , por sua vez, observou-se renda média bastante inferior $(9,2$ SM) (Tabela 5.2).

A presença de domicílio quitado foi inferior à medida que se avançou do conglomerado 1 para o 5 (Tabela 5.2).

O coeficiente de Gini mostrou-se inferior no conglomerado $1(0,460)$ e maior no $5(0,505)$ (Tabela 5.2).

O risco de óbito por câncer bucal e por glândulas salivares no Município de São Paulo foi menor nas regiões em que o coeficiente de Gini se mostrou inferior (menor desigualdade na distribuição de renda). 


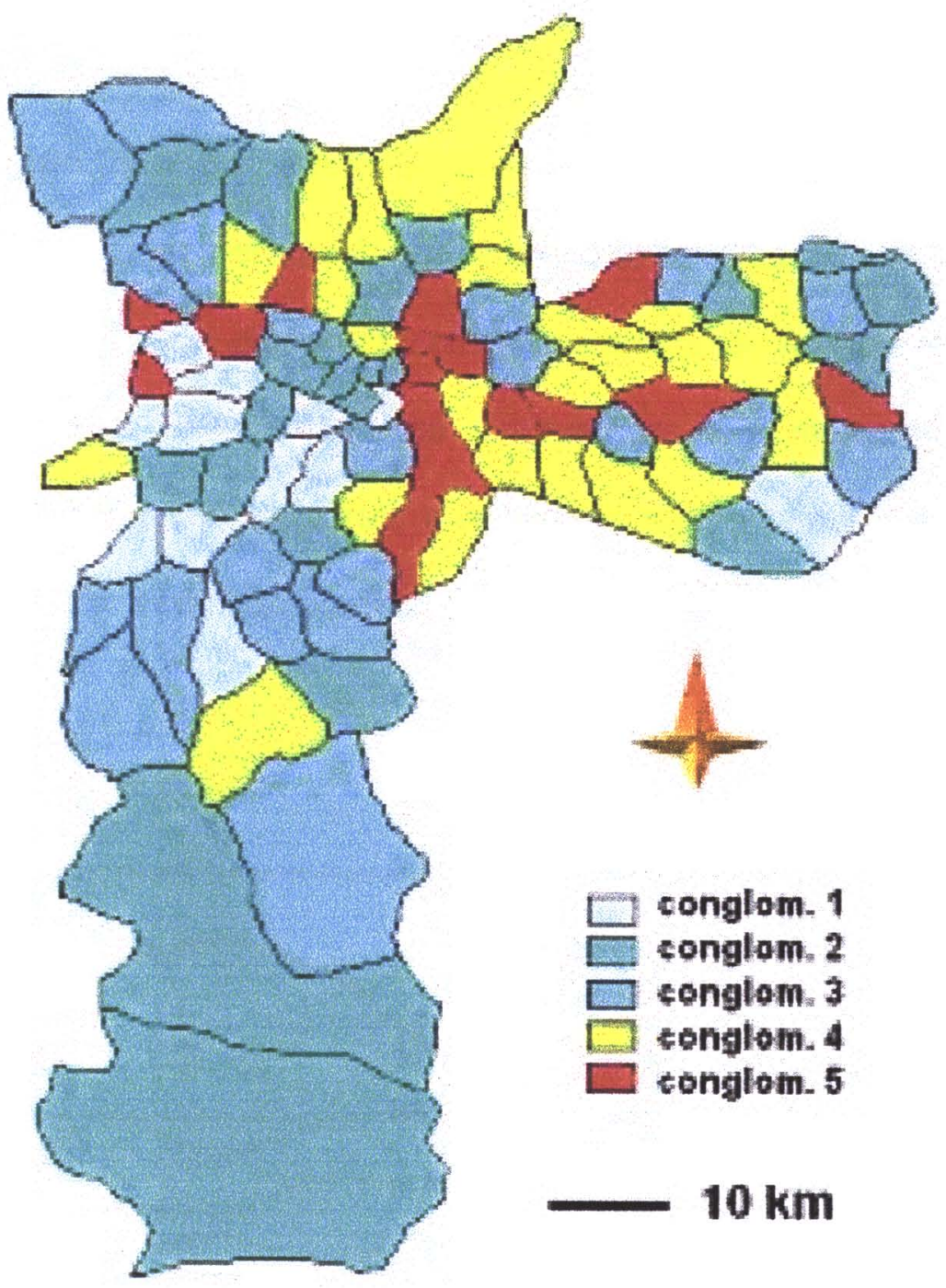

Figura 5.11. Distribuição espacial dos distritos segundo o coeficiente de mortalidade por câncer bucal e glândulas salivares. Município de São Paulo, 2002. 
A Figura 5.11 mostra a distribuição espacial do risco de óbito por câncer bucal e glândulas salivares nos diversos distritos da cidade. Observase que a região leste da cidade possui grande concentração de distritos pertencentes ao conglomerado 4, que apresenta o segundo maior risco de óbito por câncer bucal e glândulas salivares na cidade. A região central do município concentra maior número de distritos com risco maior de óbito por câncer bucal e glândulas salivares, e a mesma região também, agrega os distritos com menor risco, juntamente com a região oeste da cidade.

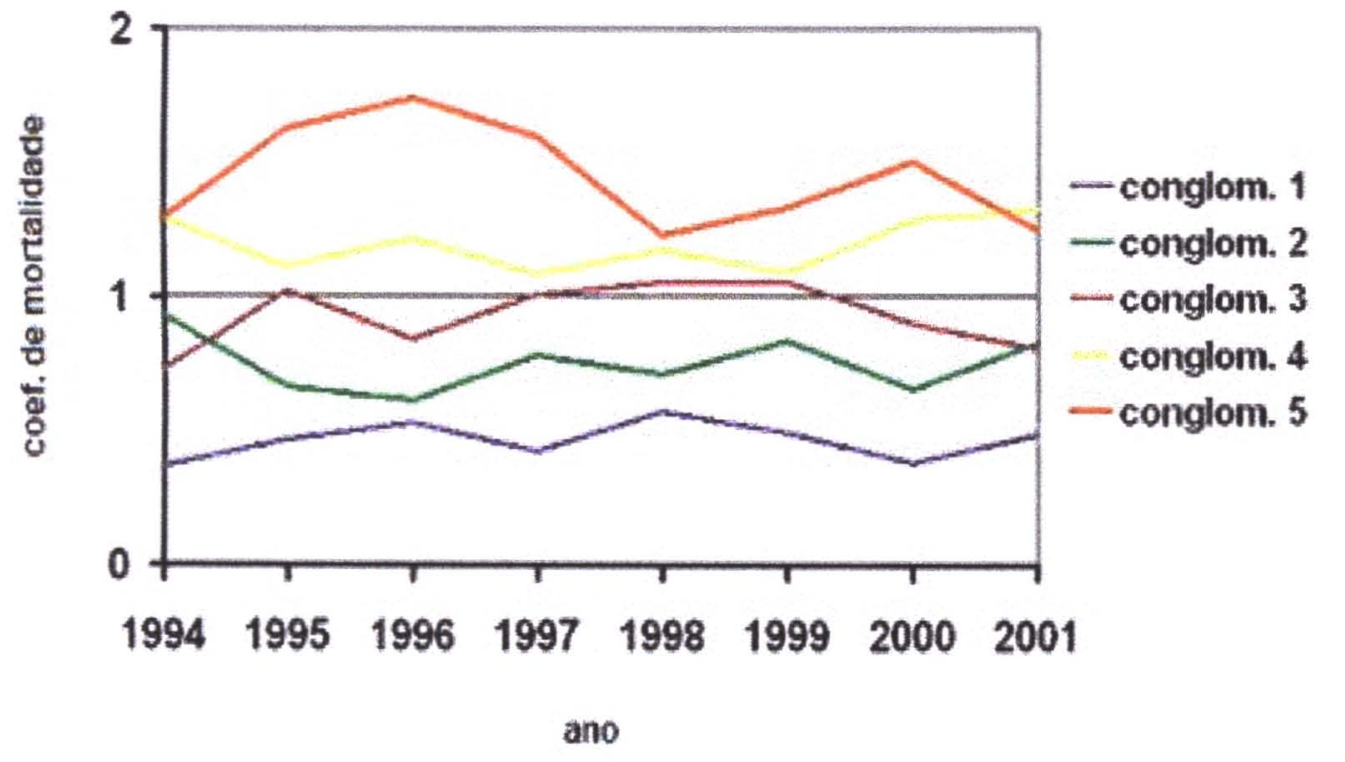

Figura 5.12. Série temporal da tendência dos óbitos por câncer bucal e glândulas salivares segundo conglomerados. Município de São Paulo, 19942001.

A Figura 5.12 mostra a evolução dos óbitos por câncer bucal e glândulas salivares no período de 1994 a 2001, segundo conglomerados do município de São Paulo. Pôde-se observar que a maior proporção de óbitos 
nos conglomerados 4 e 5 , se manteve estável durante o período estudado, o mesmo se observando para os conglomerados com coeficiente de mortalidade menos elevado.

Tabela 5.3. Coeficientes de correlação ' $r$ ' de Pearson dos indicadores socioeconômicos com o coeficiente padronizado de mortalidade por câncer bucal e glândulas salivares, Município de São Paulo, 1980-2000.

\begin{tabular}{lcc}
\hline \multicolumn{1}{c}{$\begin{array}{c}\text { Coeficientes de correlação com o risco de } \\
\text { óbito por câncer bucal }\end{array}$} & $\begin{array}{c}\text { Nivel de } \\
\text { Coef. ' } r \text { ' Pearson }\end{array}$ & \begin{tabular}{l} 
significância \\
\hline Anos estudo
\end{tabular} \\
Chefe sem instrução ou $\mathbf{1}^{\circ}$ grau incompleto & $-0,238$ & $\mathrm{p}=009$ \\
Chefe com $\mathbf{2}^{\circ}$ grau completo & 0,200 & $\mathrm{p}=0,025$ \\
Chefe com formação universitária & $-0,234$ & $\mathrm{p}=0,011$ \\
Renda média & $-0,341$ & $\mathrm{p}<0,001$ \\
Renda mediana & $-0,362$ & $\mathrm{p}<0,001$ \\
Renda média per capita & $-0,349$ & $\mathrm{p}<0,001$ \\
Domicílio quitado & $-0,376$ & $\mathrm{p}<0,001$ \\
Coeficiente de Gini & $-0,268$ & $\mathrm{p}=0,004$ \\
\hline
\end{tabular}

Quanto melhor a condição socioeconômica, mensurada por meio de renda, possibilidade de possuir casa própria, e grau de instrução do chefe da família, menor o risco de óbito por câncer bucal e glândulas salivares (Tabela 5.3). O coeficiente de correlação " $r$ " de Pearson apresentou-se inversamente proporcional ao risco de óbito por câncer bucal e glândulas salivares na cidade; o grau de instrução do chefe da família também apresentou correlação, bem como a renda média, mediana, per capita, domicílio quitado e coeficiente de Gini. Para todas as análises realizadas e anteriormente citadas, observou-se correlação estatisticamente significativa. 
Tabela 5.4. Razão entre os coeficientes de mortalidade dos conglomerados com pior condição socioeconômica com os de melhor condição socioeconômica em relação às localizações anatômicas causadoras de óbitos por câncer bucal e glândulas salivares no Município de São Paulo, 2002.

\begin{tabular}{lr}
\hline Lábio & 2,37 \\
Língua & 1,66 \\
Assoalho da boca & 1,63 \\
Gengiva ' & 1,32 \\
Glândulas salivares & 1,41 \\
Palato & 1,22 \\
Não especificado & 1,51 \\
Mucosa oral e vestíbulo da boca & 2,38 \\
\hline Total & 1,58 \\
\hline
\end{tabular}

$\mathrm{Na}$ Tabela 5.4, observa-se que o coeficiente de mortalidade por câncer bucal e glândulas salivares nos conglomerados 4 e 5 foi de 1,58 a mais que nos conglomerados 1,2 e 3 , para todas as localizações anatômicas de ocorrência. Em algumas localizações anatômicas, essa situação foi ainda mais pronunciada, como lábio e mucosa oral e vestíbulo da boca. A identificação dessas localizações anatômicas ajuda a esclarecer quais são as fontes das diferenças encontradas entre elas, ou seja, quais são os tipos de câncer que contribuem para demarcar a desigualdade entre as áreas. Palato, por outro lado, esteve distribuído de modo mais homogêneo, na análise comparativa entre as áreas 1, 2 e 3, em relação às áreas 4 e 5 . 


\section{DISCUSSÃO}

MARMOT (1999) estima que em 2020, para todas as regiões do mundo, doenças crônicas, incluindo cardiovascular, câncer e doenças respiratórias serão causas mais importantes de morte que o grupo que inclui mortes por infecções, perinatais, nutricionais e maternas.

O INCA (2002) estimou para o Brasil que, para o ano de 2002, entre homens, o câncer de pulmão seria a primeira causa de morte entre os diversos tipos de cânceres existentes, seguido de câncer de próstata, estômago, esôfago, cólon e reto. O câncer de boca ocuparia a sexta posição entre as estimativas de óbito para o sexo masculino. Entre as mulheres, o INCA estimou, para o mesmo ano, que o principal tipo de câncer que levaria a óbito seria o de mama, seguido pelo câncer de pulmão, cólon e reto, colo do útero e estômago, sendo que o câncer de boca ocuparia a $8^{a}$ posição.

Assim, o câncer bucal estaria entre as 8 principais causas de óbitos por câncer no pais, justificando a relevância de estudos que detalhem com maior precisão não apenas as localizações anatômicas de maior ocorrência, como também outros fatores relacionados com a sua prevalência.

No presente estudo, encontrou-se que a tendência global de óbitos por câncer bucal e glândulas salivares manteve-se estável no período de 1980 a 2000, observando-se que houve um decréscimo de óbito de lábio e 
gengiva. CHEN et al. (1991) encontraram estabilidade na ocorrência de câncer de boca entre 1935 e 1964 no Estado do Connecticut, Estados Unidos, com declinio gradual no início dos anos 80. Para o Município de São Paulo, no presente estudo, o coeficiente de mortalidade por câncer bucal e glândulas salivares no período de 1980 a 2000 apresentou-se um pouco acima de 2,0 por 100.000 habitantes, sendo inferior aos achados de FISCHMAN (1985), que encontrou um coeficiente global de 3,4 por 100.000 habitantes na população dos Estados Unidos. Ao comentar a tendência de declínio do câncer bucal encontrada naquele país no período de 1937 e 1971, o autor atribuiu tal achado à diminuição da prevalência de câncer de lábio.

O câncer de língua foi responsável, no presente estudo, pela maioria dos óbitos ocorridos, com 1945 casos de óbitos (49,85\%). Ao câncer de língua, seguiu-se partes não especificadas da cavidade bucal, com 660 óbitos (16,91\% do total). NEVES (1994) estudou os óbitos por câncer bucal no Estado de São Paulo entre 1979 e 1982, e também encontrou que o câncer de língua foi o que apresentou maior ocorrência, com $48 \%$ dos óbitos. Já FRANCO et al. (1993), ao analisar retrospectivamente a procura por atendimento no Hospital A.C. Camargo no Municipio de São Paulo no periodo de 1953 a 1980, observaram que câncer de lábio foi responsável por $40,8 \%$, seguido por câncer de língua $(20,8 \%)$ dentre os casos diagnosticados como câncer de boca.

FISCHMAN (1985) relata que, nos Estados Unidos, no período de 1973 a 1977, 18\% dos óbitos de câncer bucal foram atribuídos ao câncer de 
língua, seguido por $17 \%$ de câncer de lábio e $8 \%$ por câncer de glândulas salivares maiores. $\mathrm{O}$ autor comentou que houve tendência de declínio para os óbitos por câncer de lábio que tem sido observada por diversas pesquisas naquele pais. Talvez tal achado se deva à facilidade de diagnóstico da lesão, bem como conscientização da população sobre os perigos da exposição prolongada a raios solares.

PINDBORG (1977) também encontrou tendência de decréscimo para câncer de lábio ao analisar o Registro de Câncer da Noruega publicado em 1973, destacando ainda que o câncer de lábio foi 20 vezes mais freqüente entre homens do que em mulheres. Houve decréscimo na incidência de câncer de lábio nos Estados Unidos entre 1976 e 1987, segundo KLEINMAN et al. (1993). SU et al. (1999) encontraram tendência de aumento de câncer de lábio, cavidade bucal e faringe entre homens japoseses entre 1950 e 1994, sendo que no período de 1990 a 1994 o coeficiente de mortalidáde foi de 3,30 por 100.000 habitantes, acima do presente estudo, que encontrou um coeficiente de 2,2. MORSE et al. (1999), por sua vez, observaram declínio das taxas de ocorrência de câncer de lábio no Estado de Connecticut, Estados Unidos, entre 1935 e 1994.

Partes não especificadas da cavidade oral foi o responsável pela única tendência de aumento no período estudado no município de São Paulo. Tal achado pode sugerir ocorrência de diagnóstico tardio para o câncer de boca; KENT e SMITH (1984), apud FISCHMAN (1985) relataram que $60 \%$ dos carcinomas detectados eram examinados pela primeira vez em estágio bastante avançado. Outra possibilidade é a de que, ao 
preenchimento do atestado de óbito, não se esteja identificando corretamente a localização anatômica que deu origem à lesão, aumentando o volume de casos codificados como C06.9 segundo a CID-10, ou seja, partes não especificadas da cavidade bucal.

Houve um total de 3.902 óbitos por câncer bucal e glândulas salivares no Município de São Paulo entre 1980 e 2000, e estudos se fazem necessários para verificar a viabilidade de aumento da capacidade dos serviços de saúde em absorver o aumento, em números absolutos, da demanda por tratamento. FISCHMAN (1985) destaca que futuramente, haverá maior demanda por serviços de atendimento a doenças crônicas, e conseqüentemente câncer bucal, devido ao processo de envelhecimento da população americana. FRANCO et al. (1993) destacam que vários fatores são responsáveis pela decisão do paciente por procurar atendimento: sexo, raça, condição socioeconômica e fatores culturais.

Estudos sobre a epidemiologia do câncer bucal incluem diferentes localizações anatômicas, e constantemente apresentam dados unificados para as diversas localizações. Alguns autores apresentam os coeficientes de mortalidade por câncer bucal juntamente com os da faringe e orofaringe; outros, excluem lábio e glândulas salivares; MOORE et al. (2000) listam uma série de trabalhos que utilizaram diversas terminologias para a definição de câncer bucal. Assim, JOHNSON (1991) relata a necessidade de padronizar definições, coleta de dados, mensurações de resultados e análises estatísticas para viabilizar a comparação dos resultados de óbitos por câncer bucal em todo o mundo. 
Para a execução da presente pesquisa, os códigos das causas de óbito foram captados, até 1995, da nona edição da CID; a partir de 1996, utilizou-se a padronização da décima edição. Tal fato certamente não prejudicou a análise de tendência realizada. SANTO (2000), avaliou a equivalência da Classificação Internacional de Doenças entre as duas versões (CID-9 e CID-10) e explica que

"a quebra de comparabilidade mais importante para as estatísticas de mortalidade foi devida ao deslocamento de pneumonia e da broncopneumonia, causas básicas de morte segundo a nona revisão, para causas na décima revisão principalmente dos capítulos das doenças do aparelho circulatório, em particular doenças cerebrovasculares, e para os capítulos das doenças infecciosas e parasitárias e do sistema nervoso." (SANTO, 2000, p. 28)

Em relação a gênero, o presente estudo encontrou que homens foram mais acometidos que mulheres por óbitos por câncer bucal e de glândulas salivares, em proporção de 3:1. SWANGO (1996), ao realizar pesquisa epidemiológica sobre câncer de boca e de faringe nos Estados Unidos, entre 1973 e 1992, encontrou incidência de 2,5 vezes maior para homens que para mulheres. Tal achado foi semelhante ao observado por FISCHMAN (1985) para a população americana, entre os períodos de 1937-39 e 196971; o autor relata, para aquele país, um coeficiente de mortalidade de 5,9 para homens e 1,9 para as mulheres (3:1), por 100.000 habitantes. 
KLEINMAN et al. (1993) também comentam sobre a maior prevalência de câncer bucal entre homens que entre mulheres, em todo o mundo. FRANCO et al. (1993), em estudo de base hospitalar, encontraram que homens foram mais acometidos que mulheres, em proporção de 6:1, e finalmente NEVES (1994), para o estado de São Paulo, 5:1.

BARATA (2000), ao comentar a determinação social do processo saúde-doença, bem como a origem das desigualdades em saúde, explica que existem diferenças que não são, necessariamente, injustas; além disso, levanta a questão do conceito de eqüidade, e que este não seria capaz de contemplar todas as necessidades de diferentes pessoas, já que cada indivíduo possui necessidades diferentes.

MARMOT e WILKINSON (1999), ao comentar a respeito de iniqüidades em saúde e uso de tabaco, destacam que a possibilidade de vir a ser fumante aumenta significativamente naquelas pessoas pertencentes a grupos ocupacionais mais baixos, naquelas que vivem em casas alugadas, sem a possibilidade de possuir carro próprio, entre as que estão desempregadas e onde se observa altos indicadores de aglomeração domiciliar.

WILKINSON (1996) destaca ainda que as pessoas mais pobres nos países desenvolvidos chegam a atingir taxas de mortalidade anual entre $2 \mathrm{e}$ 4 vezes mais altas que as pessoas mais ricas da mesma sociedade.

VIANA et al. (2001) comentam que 
"A disponibilidade de estudos sobre eqüidade em saúde ainda é desproporcional à importância do assunto. Parte da escassez parece associada à carência e, sobretudo, à irregularidade de dados específicos. Incrementar o desenvolvimento de sistemas de informações integrados, confiáveis, abrangentes e acessiveis que possibilitem a análise das desigualdades em saúde em suas diferentes dimensões além da geográfica, facilitaria a definição de prioridades setoriais e melhoraria o planejamento e a avaliação dos programas." (p.172).

Diversos estudos têm associado condição de saúde com iniqüidade. Em artigo que descreve os métodos de mensuração das desigualdades em saúde, SCHNEIDER et al. (2002) destacam a importância do coeficiente de Gini para estimar condição de saúde em diversos grupos populacionais. O'HANLON (1997), ao discutir a ligação entre câncer bucal e privação material, utilizou renda familiar, aglomeração domiciliar, posse de automóvel e níveis de desemprego, associados ao risco de óbito e incidência de câncer bucal no Noroeste da Inglaterra.

No presente trabalho, observou-se coincidência entre o aumento do coeficiente de Gini para cada conglomerado, e aumento do risco de óbito por câncer bucal e glândulas salivares.

Os achados da mortalidade por câncer bucal e glândulas salivares no Município de São Paulo confirmam o que os trabalhos atualmente publicados têm discutido: quanto pior a renda familiar, grau de instrução, 
aglomeração domiciliar, maior o risco de óbito por câncer bucal. KOGEVINAS et al. (1997), por meio da "International Agency for Research on Cancer" (IARC) publicaram documento onde se analisou a associação entre iniqüidade e câncer, tanto em países desenvolvidos, quanto em desenvolvimento. $O$ documento relata estreita relação entre pobreza e prevalência de óbitos por câncer, e que nos países em desenvolvimento, as taxas de sobrevivência de pacientes a partir do diagnóstico é 1/3 (um terço) em relação aos países industrializados. Tal afirmação poderia ajudar a esclarecer os motivos pelos quais tem-se encontrado, em São Paulo, tendência de aumento de óbitos por câncer bucal para partes não especificadas da cavidade bucal: diagnóstico tardio.

A divisão espacial do Município de São Paulo em conglomerados com riscos semelhantes de óbitos para o câncer bucal associou-se com indicadores de condição socioeconômica. BARROS (1997) analisou a mortalidade no Município de Campinas - SP, a partir de 4 conglomerados segundo condições socioeconômicas, também encontrando coeficientes de mortalidade maiores em áreas economicamente menos favorecidas. GUPTA et al. (1984) acompanharam 10.169 pessoas durante 10 anos no Distrito de Srikakulam, Índia, realizando exames bucais constantes e registrando hábitos a respeito do uso do tabaco. Além de observarem uma estreita relação entre a prática do "reverse smoking" e mortalidade por câncer de boca, os autores destacaram a importância da baixa condição socioeconômica da população estudada, que certamente influenciou o alto coeficiente de mortalidade por câncer bucal na região. LOCKER (2000) 
comenta que associação entre condição socioeconômica e saúde, incluindo saúde bucal, já está bem estabelecida.

MACFARLANE et al. (1996) encontraram que a taxa de sobrevivência para os diagnósticos de câncer bucal na Escócia entre 1968 e 1987 foi menor entre os indivíduos provenientes de áreas geográficas com pior condição socioeconômica, e ainda destacam que os incrementos ocorridos na incidência por câncer bucal têm sido observados nesses grupos. WILKINSON (1997) afirma que independente do grau de desenvolvimento do país, as populações que apresentam menores diferenças de renda em sua população tendem a usufruir de melhor saúde.

Em publicação sobre a importância dos sistemas de informação geográfica para monitorar as desigualdades em saúde, LOYOLA et al. (2002) destacam que tal recurso é necessário não somente para a realização de análises entre países e continentes, mas principalmente, para a identificação de grupos e áreas com os maiores problemas em escala local.

Diversos estudos têm sido publicados abordando mortalidade por diversos tipos de câncer e áreas geográficas, culminando constantemente com achados semelhantes: quanto pior a condição socioeconômica e a distribuição de renda, maior o coeficiente de mortalidade para a doença em estudo (PANACHÃO, 1995, FARDO, 1999, GOMES, 2000, REIS, 2001, ANTUNES et al., 2001); tal observação também tem sido encontrada para outras doenças bucais, como a cárie dentária (BALDANI et al., 2002, ANTUNES et al., 2002). 
Observou-se, no presente estudo, que o coeficiente de mortalidade por câncer bucal e glândulas salivares no Município de São Paulo esteve associado negativamente com rendas média, mediana, per capita e grau de instrução do chefe da família.

Apesar disso, nem todos os distritos do Município de São Paulo apresentam características de homogeneidade. O Distrito do Morumbi, por exemplo, onde vivem pessoas com alto poder aquisitivo, foi classificado como parte do conglomerado 2. Isso pode ser atribuído à convivência, no mesmo bairro, com pessoas morando em bolsões de pobreza.

SPOSATI (1996) destaca que “... não são muitos os dados disponiveis que detectam as manifestações da exclusão social na forma abrangente do conceito adotado. E (...) são mais raros ainda os que permitem desagregar suas informações pelos 96 Distritos de São Paulo." 


\section{CONCLUSÕES}

Os homens foram atingidos em maior proporção que as mulheres pela mortalidade por câncer bucal e glândulas salivares, numa proporção aproximada de 3:1.

O câncer de língua foi responsável por quase $50 \%$ de todos os óbitos associados a câncer bucal no período estudado.

A tendência de mortalidade por câncer bucal e glândulas salivares manteve-se estável no período de 1980 a 2000 no Município de São Paulo. Algumas localizações anatômicas (gengiva e lábio) apresentaram uma redução no coeficiente de mortalidade por câncer bucal.

Observou-se tendência estável para assoalho da boca, glândulas salivares, língua, palato e região retromolar. Houve tendência de aumento para os óbitos classificados como partes não especificadas da cavidade bucal.

Distritos com maior proporção de óbitos possuiam piores indicadores de desenvolvimento social, sugerindo que o coeficiente de mortalidade por câncer bucal e glândulas salivares foi associado de maneira estreita com iniqüidades sociais relacionadas à saúde. 


\section{REFERÊNCIAS}

1 Almeida Filho $N$, Rouquayrol $M Z$. Introdução à epidemiologia. Rio de Janeiro:Medsi, 2002.

2 Antunes JLF, Biazevic MGH, Araujo ME, Tomita NE, Chinellato LEM, Narvai PC. Trends and spacial distribution of oral cancer mortality in São Paulo, Brazil, 1980-1998. Oral Oncology 2001; 37(4):345-350.

3 Antunes JLF, Frazão P, Narvai PC, Bispo CM, Pegoretti T. Spacial analysis to identify differentials in dental needs by area-based measures. Community Dent Oral Epidemiol 2002; 30:133-142.

4 Antunes JLF, Waldman EA. Trends and spatial distribution of deaths of children aged 12-60 months in São Paulo, Brazil, 1980-98. Bull WHO 2002; 80(5):391-398.

5 Baldani MH, Narvai PC, Antunes JLF. Cárie dentária e condições socioeconômicas no Estado do Paraná, Brasil, 1996. Cad. Saúde Pública 2002; 18(3):755-763.

6 Barata RB. Iniqüidade e saúde: a determinação social do processo saúdedoença. Rev. da USP 2001; 51:138-145.

7 Barros MBA. Epidemiologia e superação das iniqüidades em saúde. In: Barata RB (organizadora). Eqüidade e saúde: contribuições da epidemiologia. Rio de Janeiro:Fiocruz/Abrasco, 1997. p. 161-176.

8 Barros RP, Henriques R, Mendonça R. A estabilidade inaceitável: desigualdade e probreza no Brasil. Brasil:Brasília:IPEA (Instituto de Pesquisa Econômica Aplicada), Ministério do Planejamento, Orçamento e Gestão, 2001. 
9 Bloom G. Equity in health in unequal societies: towards health equity during rapid social change. Institute of Development Studies, IDS Working Paper 112, 2000.

10 Burt BA, Eklund AS. Oral cancer and other oral conditions. In: Dentistry, dental practice and the community. 5. ed. Philadelphia:W.B. Saunders Company, 1999.

11 Casas JA. Promover la equidad em salud y desarrollo humano en la cooperación técnica en salud en las Américas: la perspectiva de la Organización Panamericana de la Salud. OPS/OMS, 1999, mimeo.

12 Castellanos PL. Perfis de mortalidade, nivel de desenvolvimento e iniqüidades sociais na Região das Américas. In: Barata RB (organizadora). Eqüidade e saúde: contribuições da epidemiologia. Rio de Janeiro:Fiocruz/Abrasco, 1997. p. 137-160.

13 Castillo-Salgado C, Schneider C, Loyola E, Mujica O, Roca A, Yerg T. Measuring health inequalities: gini coefficient and concentration index. Epidemiological Bulletin / PAHO 2001; 22(1):3-4.

14 Chen J, Eisenberg E, Krutchkoff DJ, Katz RV. Changing trends in oral cancer in the United States, 1935-1985: a Connecticult study. J Oral Maxillofac Surg 1991; 49(11):1152-58.

15 Constance P. Uma medida do infortúnio. Renda, desigualdade, e um homem chamado Gini. Available from <URL: http://www.iadb.org/idbamerica/archive/stories/1998/por/11-12g.htm>. [2003 Mar 16]

16 Dachs N. Inequidades en salud: como estudiarlas. In: Restrepo $H$, Málaga $H$. Promoción de la salud: cómo construir vida saludable. México:Ed. Médica Panamericana, 2001.

17 Escorel S. Os dilemas da eqüidade em saúde: aspectos conceituais. Disponivel em < http://www.opas.org.br/servico. $>$ [15 dez 2002] 
18 Fardo MG. Câncer de próstata: mortalidade entre os residentes no estado do Rio Grande do Sul no período de 1970 a 1992. São Paulo; 1999. [Dissertação de Mestrado - Faculdade de Saúde Pública da USP].

19 Ferreira $A B H$. Novo Aurélio século $X X I$ : o dicionário da língua portuguesa. 3ed., Rio de Janeiro:Nova Fronteira; 1999.

20 Fischman SL. Oral health status in the United States: oral cancer and soft tissue lesions. J Dent Educ 1985; 49:379-84.

21 Franco EL, Dib LL, Pinto DS, Lombardo V, Contesini H. Race and gender influences on the survival of patients with mouth cancer. $\mathrm{J}$ Clin Epidemiol 1993; 46(1):37-46.

22 Fundação Sistema Estadual de Análise de Dados (SEADE). Disponivel em <URL: http://www.seade.gov.br> [2001 Mar 11]

23 Gakidou EE, Murray CJL, Frenk J. Defining and measuring health inequality: an approach based on the distribution of health expectancy. Bull WHO 2000; 78(1):42-54.

24 Gaynor PE, Kilkpatrick RC. Introduction to time-series modelling and forecasting in business and economics. New York:McGraw-Hill, 1994.

25 Goldbaum M. A epidemiologia em busca da eqüidade em saúde. In: Barata RB et al.(organizadores). Eqüidade e saúde: contribuições da epidemiologia. Rio de Janeiro:Fiocruz/Abrasco, 1997. p.63-80.

26 Gomes JO. Distribuição espacial da mortalidade por câncer de mama feminino no estado de São Paulo, 1991 a 1995. São Paulo; 2000. [Tese de Doutorado - Faculdade de Saúde Pública da USP].

27 Gupta PC. Epidemiologic study of the association between alcohol habits and oral leukoplakia. Community Dent Oral Epidemiol 1984; 12(1):47-50.

28 Gupta PC, Mehta FS, Pindborg JJ. Mortality among reverse chutta smokers in south India. Br Med J (Clin Res ED) 1984; 289(6449):865-6. 
29 Gupta PC. Leukoplakia and incidence of oral cancer. J Oral Pathol Med 1989; 18(1):17.

30 Gupta PC, Mehta FS, Pindborg JJ, Aghi MB, Bronsle RB, Daftary DK et al. Intervention study for primary prevention of oral cancer among 36000 Indian tobacco users. Lancet 1986; 1(8492):1235-8.

31 Gupta PC, Mehta FS, Pindborg JJ, et al. Primary intervention trial of oral cancer in India: a 10-year follow-up study. J Oral Pathol Med 1992; 21:433-9.

32 Gwatkin DR. Health inequalities and the health of the poor: what do we know? What can we do? Bull WHO 2000; 78(1):3-18.

33 Hakansson N, Floderus B, Gustavsson P, Feychting M, Hallin N. Occupational sunlight exposure and cancer incidence among Swedish construction workers. Epidemiology 2001, 12: 552-557.

34 IBGE. INSTITUTO BRASILEIRO DE GEOGRAFIA E ESTATÍSTICA. Censo populacional 2000. Disponivel em <URL: http://www.ibge.gov.br>. [2002 Nov 17]

35 INCA. Instituto Nacional de Câncer. O câncer no Brasil. Disponível em <URL: http://www.inca.gov.br/cancer/epidemiologia/epidemiologia do cancer.html>. [2002 Nov 17]

36 INCA. Instituto Nacional de Câncer. Estimativas da incidência e mortalidade por câncer no Brasil. Rio de Janeiro:Ministério da Saúde/INCA, 2002.

37 ISEqH. International Society for Equity in Health. Toronto declaration on equity in health. Rev Panam Salud Pública 2002; 12(6): 465-467.

38 Jarvis MJ, Wardle J. Social patterning of individual health behaviours: the case of cigarette smoking. In: Marmot M, Wilkinson RG. Social determinants of health. Oxford:Oxford University Press, 1999. p.240-255.

39 Jitomirski F. Câncer bucal. In: Pinto VG. Saúde bucal coletiva. 4ed. São Paulo:Santos, 2000. p.445-56. 
40 Johnson NW. Orofacial neoplasms: global epidemiology, risk factors and recommendations for research. Int Dent J 1991; 41:365-75.

41 Johnson RA, Wichern DW. Applied multivariate statistical analysis. Upper Saddle River:Prentice Hall, 1998.

42 Jones CM, Taylor GO, Whittle JG, Evans D, Trotter DP. Water fluoridation, tooth decay and social deprivation measured by the Jarman score: analysis of data from British dental surveys. Brit Med J 1997; 315:514-517.

43 Kleinman DV, Swango PA, Pindborg JJ, Gupta PC. Toward assessing trends in oral mucosal lesions: lessons learned form oral cancer. Adv Dent Res 1993; 7(1):32-41.

44 Kogevinas $M$, Pearce $N$, Susser $M$, Boffetta $P$. Social inequalities and cancer. Lyon:IARC, 1997. [IARC Scientific Publications no. 138]

45 Laurell AC. Impacto das políticas sociais e econômicas nos perfis epidemiológicos. In: Barata RB (organizadora). Eqüidade e saúde: contribuições da epidemiologia. Rio de Janeiro:Fiocruz/Abrasco, 1997. p. 83-101.

46 Levin J. Estatística aplicada às ciências humanas. São Paulo:Harbra, 1978.

47 Locker D. Deprivation and oral health: a review. Community Dent Oral Epidemiol 2000; 28(3):161-166.

48 Loyola E, Castillo-Salgado C, Nájera-Aguilar P, Vidaurre M, Mujica OJ, Martinez-Piedra R. Los sistemas de información geográfica como herramienta para monitorear las desigualdades de salud. Rev Panam Salud Pública 2002; 12(6): 415-428.

49 Lucchese PTR. Eqüidade na gestão do Sistema Único de Saúde. [Trabalho apresentado como pôster no VI Congresso Brasileiro de Saúde Coletiva, agosto de 2000, Salvador, Bahia, Brasil].

50 Macedo AC, Paim JS, Silva LMV, Costa MCN. Violência e desigualdade social: mortalidade por homicídios e condições de vida em Salvador, Brasil. Rev Saúde Pública 2001; 35(6):515-522. 
51 Macfarlane GJ, Sharp L, Porter S, Francheschi S. Trends in survival from cancers of the oral cavity and pharynx in Scotland: a clue as to why the disease is becoming more common? Br J Cancer 1996; 73(6):805-8.

52 Maciel S, Lessa F, Rodrigues CS. Mortalidade por câncer bucal e desigualdades sociais nas Capitais brasileiras, 1980 e 1991. Revista Brasileira de Odontologia em Saúde Coletiva 2000; 1: 51-61.

53 Macinko JA, Starfield B. Annotated bibliography on equity in health, 19802001. International Journal for Equity in Health 2002; 1:1. Available from <URL: http://www.equityhealthj.com/content/1/1/1 > [2003 Jan 15]

54 Marmot M. Introduction. In: , Wilkinson RG. Social determinants of health. Oxford:Oxford University Press, 1999. p.3.

55 Marmot M, Wilkinson RG. Social determinants of health. Oxford:Oxford University Press, 1999. 291p.

56 Minayo MCS. Condiciones de vida, desigualdad y salud a partir del caso brasileño. In: Briceño-León R. (coord.). Salud y eqüidad: una mirada desde las ciencias sociales. Rio de Janeiro:Fiocruz, 2000. p. 55-71. Ministério da Saúde. Instituto Nacional de Câncer. Coordenação de Programas de Controle de CÂNCER - PRO-ONCO. O Problema do Câncer no Brasil. 4.ed. Rio de Janeiro, 1997.

58 Mirra AP, Latorre MRDO, Veneziano $\mathrm{DB}$, eds. Incidência de câncer no município de São Paulo, Brasil. Brasilia:Ministério da Saúde, 1999.

59 Monteiro MFG. Transição demográfica e seus efeitos sobre a saúde da população. In: Barata RB (organizadora). Eqüidade e saúde: contribuições da epidemiologia. Rio de Janeiro:Fiocruz/Abrasco, 1997. p. 189-204.

60 Moore S, Johnson N, Pierce A, Wilson D. The epidemiology of lip cancer: a review of global incidence and aetiology. Oral Dis 1999; 5(3): 185-195.

61 Moore SR, Johnson NW, Pierce AM, Wilson DF. The epidemiology of mouth cancer: a review of global incidence. Oral Dis 2000; 6:65-74. 
62 Moore SR, Pierce AM, Wilson DF. "Oral cancer" - the terminology dilemma. Oral Dis 2000; 6:191-193.

63 Morris S. A desigualdade e a saúde pública. Rev. Saúde Públ. 1997; 31(6):543-544.

64 Morse DE, Pendrys DG, Neely AL, Psoter WJ. Trends in the incidence of lip, oral and pharyngeal cancer: Connecticut, 1935-94. Oral Oncology 1999; 35(1):1-8.

65 Neves LHM. Câncer de boca: mortalidade entre os residentes no Estado de São Paulo no período de março de 1979 a fevereiro de 1982. São Paulo; 1994. [Tese de Doutorado - Faculdade de Saúde Pública da USP].

66 O'Hanlon S, Forster DP, Lowry RJ. Oral cancer in the North-East of England: incidence, mortality trends and the link with material deprivation. Community Dent Oral Epidemiol 1997; 25(5):371-6.

67 Oliveira DT, Odell EW. Diagnóstico precoce e prevenção do câncer de boca. In: Buischi YP. Promoção de saúde bucal na clínica odontológica. São Paulo:Artes Médicas:EAP:APCD, 2000. p.279-293.

68 Organização Mundial da Saúde (OMS). Classificação internacional das doenças, 9a. revisão (CID-9), São Paulo:Edusp, 1993.

69 Organização Mundial da Saúde (OMS). Classificação internacional das doenças e problemas relacionados à saúde, $10^{\mathrm{a}}$. revisão (CID-10). São Paulo:Edusp, 1999.

70 Panachão MRI. Distribuição espacial da mortalidade por câncer ginecológico no município de São Paulo em 1992. São Paulo; 1995. [Dissertação de Mestrado - Faculdade de Saúde Pública da USP].

71 Patussi MP, Marcenes W, Croucher R, Sheiham A. Social deprivation, income inequality, social cohesion and dental caries in Brazilian school children. Soc Sci Med 2001; 53:915-925. 
72 Pearce N. Classe social e câncer. In: Barata RB, Barreto ML, Almeida Filho N, Veras RP (orgs.). Eqüidade e saúde: contribuições da epidemiologia. Rio de Janeiro:Fiocruz/ABRASCO, 1997.

73 Pereira MG. Epidemiologia. Teoria e prática. Rio de Janeiro:GuanabaraKoogan, 1995.

74 Pindborg JJ. Epidemiological studies of oral cancer. Int Dent J 1977; 27:1728.

75 Pinto VG. Epidemiologia das doenças bucais no Brasil. In: Kriger L. (organizador). ABOPREV: promoção de saúde bucal. 2ed. São Paulo:Artes Médicas, 1999. p.27-41.

76 Prefeitura Municipal de São Paulo. Secretaria Municipal de Planejamento Urbano. Disponivel em <URL: http://portal.prefeitura.sp.gov.br/secretarias/planejamento >. [2001 Mar 11]

77 Reis DO. Diferenças socioeconômicas na mortalidade por neoplasias malignas no município de São Paulo, 1997. São Paulo; 2001. [Dissertação de Mestrado - Faculdade de Saúde Pública da USP].

78 Rothman KJ. Modern epidemiology. Boston:Little Brown and Company, 1986.

79 Rouquayrol MZ, Almeida Filho N. Epidemiologia \& saúde. 5 ed. Rio de Janeiro:Medsi, 1999.

80 Santo $\mathrm{AH}$. Equivalência entre revisões da Classificação Internacional de Doenças: causas de morte. Rev Saúde Públ 2000; 34(1):21-28.

81 Santos SM, Pina MF, Carvalho MS. Os sistemas de informações geográficas. In: Carvalho MS, Pina MF, Santos SM (orgs.). Conceitos básicos de sistemas de informação geográfica e cartografia aplicados à saúde. Brasilia: Organização Panamericana da Saúde / Ministério da Saúde, 2000.

82 Schneider MC, Castillo-Salgado C, Bacallao J, Mujica OJ, Roca A. Métodos de medición de las desigualdades de salud. Rev Panam Salud Pública 2002; 12(6): 398-414. 
83 Smith CJ. Global epidemiology and eatiology of oral cancer. Int Dent J 1973; 23:82-93.

84 Smith CJ, Pindborg JJ, Binnie WH, eds: Oral cancer; epidemiology, etiology, and pathology. New York:Hemisphere, 1990.

85 Sposati AO. Mapa da exclusão/inclusão social na cidade de São Paulo. São Paulo:EDUC, 1996.

86 Starfield B. Equity in health: a perspective on nonrandom distribution of health in the population. Rev Panam Salud Pública 2002; 12(6): 384-387.

87 Su WZ, Tohnai I, Kawamura T, Tamakoshi K, Wakai K, Aoki R et al. Trends in site-specific mortality from oral and pharyngeal cancer among Japanese males, 1950-1994. Oral Oncology 1999; 35(1):9-16.

88 Swango PA. Cancers of the oral cavity and pharynx in the United States: an epidemiologic overview. J Public Health Dent 1996; 56(6):309-18.

89 Tomatis L. Poverty and cancer. In: Kogevinas M, Pearce N, Susser M, Boffetta P. Social inequalities and cancer. Lyon:IARC, 1997. [IARC Scientific Publications no. 138]

90 Viana SM, Nunes A, Santos JRS, Barata RB. Medindo as desigualdades em saúde no Brasil. Uma proposta de monitoramento. Brasilia:Organização PanAmericana da Saúde, Instituto de Pesquisa Econômica Aplicada, 2001.

91 Whitehead M. The concepts and principles of equity and health. In: WHO. Targets for health for all. Copenhagen, WHO Regional Office for Europe (European Health for All Series No. 1), 1985.

92 Watt $\mathrm{R}$, Sheiham A. Inequalities in oral health: a review of the evidence and recommendations for action. British Dental Journal 1999; 187(1):6-12.

93 Wilkinson R. Unhealthy societies: the afflictions of inequality. London:Routledge, 1996. 254p.

94 Wilkinson R. Relação internacional entre eqüidade de renda e expectativa de vida. In: Barata RB (organizadora). Eqüidade e saúde: contribuições da epidemiologia. Rio de Janeiro:Fiocruz/Abrasco, 1997. p. 103-120. 
95 Winn DM, Sandberg AL, Horowitz AM, Diehl SR, Gutkind S, Kleinman DV. Reducing the burden of oral and pharyngeal cancers. Journal of the California Dental Association 1998; 26:445-51.

96 Zain RB. Cultural and dietary risk factors of oral cancer and precancer - a brief overview. Oral Oncology 2001, 37: 205-210.

97 Zanatta CR. Mortalidade por câncer de mama entre as mulheres residentes no estado de Santa Catarina, no período de 1979 a 1997. São Paulo; 2001. [Dissertação de Mestrado - Faculdade de Saúde Pública da USP]. 
ANEXO 


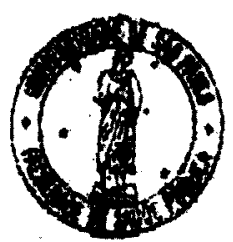

\section{Universidade de Sấo Paulo}

Faculdade de Saúde Pública

COMITE DE ÉTICA EM PESQUISA -. COEP

Av. Dr Amaldo, 715 - CEP 01246-904 - Sto Paulo - Brasil

Teletones: (55-11) 3066- 7779 - fond/fax (55-11) 3064 -7314-e-mail: mdrracasouso.br

\section{Of, COEP/51/02}

Sa $\$$ Paulo. 20 de fevereiro de 2002

Pelo presentc. informo que o Comitê de Ética tm Pesquisá da Faculdade de jaúde Pública da Universidade de Săo Paulo -COEP em sua $01^{2 / 02}$, Sessão Ordínária, ealizada em 19.02.02, analisou e aprovou, de acordo com os requisitos da Resolução 96/96, o Protocolo de Pesquisa n." 689. intitulado: "EYOLUÇẢo E DIFERENCIAIS DOCIOECONOMMTCOS DA MORTALIDADE POR CANCER BLCAL NO IUNICIPIO DE SÃO PAULO, 1980 A 2000", da pesquisadora Marta Gabriela Haye Bazevic

Atenciosamente,

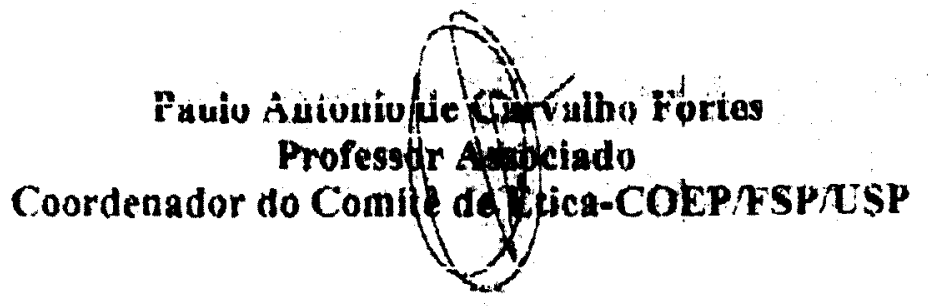

